\title{
Arterial spin-labelling and magnetic resonance spectroscopy as imaging biomarkers for detection of epileptogenic zone in non-lesional focal impaired awareness epilepsy
}

\author{
Rania Essam-el-dein Mohamed ${ }^{1 *}$, Ashraf Ali Aboelsafa ${ }^{2}$ and Rasha Mahmoud Dawoud
}

\begin{abstract}
Background: The proper identification of an epileptic focus is a pivotal diagnostic issue; particularly in non-lesional focal impaired awareness epilepsy (FIAE). Seizures are usually accompanied by alterations of regional cerebral blood flow (rCBF) and metabolism. Arterial spin labeling-MRI (ASL-MRI) and proton magnetic resonance spectroscopy $(1 \mathrm{H}-$ MRS) are MRI techniques that can, non-invasively, define the regions of cerebral perfusion and metabolic changes, respectively. The aim of the current study was to recognize the epileptogenic zone in patients with non-lesional FIAE by evaluating the interictal changes in rCBF and cerebral metabolic alterations, using PASL-MRI and 1H-MRS.

Results: For identification of the epileptogenic zone, increased ASLAI\% assessed by PASL-MRI (at a cut-off value $\geq$ 5.96\%) showed $95.78 \%$ accuracy, and increased \%AF (at a cut-off value $\geq 9.98 \%$ ) showed $98.14 \%$ accuracy, while decreased NAA/(Cho + Cr) ratio estimated by multi-voxels (MV) 1H-MRS (at a cut-off value $\geq 0.59$ ) showed $97.74 \%$ accuracy. Moreover, the combined use of PASL-MRI and MV 1H-MRS yielded 100\% sensitivity, $98.45 \%$ specificity and 98.86\% accuracy.

Conclusion: The combined use of PASL-MRI and MV 1H-MRS can be considered as in-vivo proficient bio-marker for proper identification of epileptogenic zone in patients with non-lesional FIAE.
\end{abstract}

Keywords: Arterial spin-labelling, Proton magnetic resonance spectroscopy, Focal impaired awareness epilepsy

\section{Background}

Epilepsy is one of the most common chronic neurological disorders, in which brain activity becomes abnormal, causing recurrent seizures or episodes of unusual behaviour, sensations and sometimes loss of awareness [1]. It has an estimated prevalence of about 5-15 per 1000 of people world-wide [2]. The most common type $(60 \%)$ of seizures are convulsive; one-third of them begins as generalized seizures from the start affecting both

\footnotetext{
* Correspondence: rany1997@yahoo.com

${ }^{1}$ Radiodiagnosis and Medical Imaging Department, Tanta University, Tanta, Egypt

Full list of author information is available at the end of the article
}

cerebral hemispheres, while two-thirds begin as focal seizures, that may then progress to generalized seizures. The remaining $40 \%$ of seizures is non-convulsive [3].

The focal or localization-related epilepsy, previously been referred to as partial epilepsy, may be due to lesion or non-lesion. In the non-lesional type, the lesion may not exist or may exist, but subtle and not easily differentiated from the surrounding normal brain tissue by standard imaging techniques [4]. Identification of a potential focal epileptogenic zone in such patients presents a major challenge as it is a crucial first step in the management of pharmaco-resistant seizures [5].
Springer Open
(อ) The Author(s). 2020 Open Access This article is licensed under a Creative Commons Attribution 4.0 International License, which permits use, sharing, adaptation, distribution and reproduction in any medium or format, as long as you give appropriate credit to the original author(s) and the source, provide a link to the Creative Commons licence, and indicate if changes were made. The images or other third party material in this article are included in the article's Creative Commons licence, unless indicated otherwise in a credit line to the material. If material is not included in the article's Creative Commons licence and your intended use is not permitted by statutory regulation or exceeds the permitted use, you will need to obtain permission directly from the copyright holder. To view a copy of this licence, visit http://creativecommons.org/licenses/by/4.0/. 
Imaging plays a pivotal role in the identification of the irritative zone, which is defined as a part of the cortex that creates inter-ictal spikes and provides a sign of the location of epileptogenic zone [6]. Although there is no worldwide standard imaging protocol for epilepsy among different centres, the main neuroimaging modality is magnetic resonance imaging (MRI) [7]. In non-lesion epilepsy, there are continuing imaging-based research avenues aiming at recognition of the epileptogenic zone [6], which is usually missed by routine MRI [8].

Seizure attack has become widely advocated [9]. The radionuclides techniques including single photon emission computed tomography (SPECT) and positron emission tomography (PET) were employed to detect these changes [9]. However, these techniques have been discouraged as they are expensive, need exposure to radiation and utilize radioactive contrast agents [10].

Arterial spin labelling-MRI (ASL-MRI) is a noninvasive perfusion-weighted MRI technique that utilizes magnetically labelled protons from arterial blood-water, which serve as an endogenous diffusible tracer [11]. The automated subtraction of labelled and control images creates a coloured regional cerebral blood flow ( $\mathrm{rCBF}$ ) maps and facilitates the evaluation of the cerebral perfusion changes in a non-invasive manner [12]. Moreover, proton magnetic resonance spectroscopy (1H-MRS) is a non-invasive technique that defines the regions of metabolic changes. It can precisely lateralize epileptogenic zone [13].

The aim of this study was to investigate the capability of in-vivo identification of epileptogenic zone in patients with non-lesional focal impaired awareness epilepsy (FIAE) by evaluation of the inter-ictal changes in the $\mathrm{rCBF}$ and cerebral metabolic alterations of the irritative zone, via using the ASL-MRI and the multi-voxel $1 \mathrm{H}$ MRS imaging tools of the brain.

\section{Methods}

\section{Study participants}

This prospective study was carried out in the period from October 2016 to October 2018 and included a total of 26 consecutive epileptic patients. They were referred from the Neurology Department to the Radiodiagnosis and Medical Imaging Department in our institution, for brain imaging purposes as a part of their diagnostic work up. They were 14 females and 12 males with their ages ranged from 16 to 57 years and a mean of 26.56 years. They were all clinically diagnosed to have FIAE according to the recent International League Against Epilepsy (ILAE) Classification in 2017 [14]. The conventional brain MRI of all included patients revealed no lesional findings detected (MRI-negative).

In addition to the standard exclusion criteria for MRI investigations, all patients with drug-induced epilepsy, metabolic illnesses known to affect the cerebral metabolite concentration ratios such as diabetes mellitus, which increases the cerebral myo-inositol level with elevated myo-inositol/creatine $(\mathrm{MI} / \mathrm{Cr})$ ratio [15], co-morbid neurologic disorders, previous brain surgery, head trauma or other relevant pathologies (such as stroke, psychiatric illness and mental disorders) and brain MRIpositive results (including abnormal hippocampal size, increased T2-weighted image or apparent diffusion coefficient (ADC) signal intensity related to hippocampal atrophy or mesial temporal sclerosis and space occupying lesions) were excluded from the study. Furthermore, all included patients were not-medicated during the last 3 months prior to imaging studies. All procedures performed in the current study, involving human participants, were in accordance with the ethical standards of the institutional research committee and with the 1964 Helsinki declaration and its later amendments. Moreover, the study in hand was approved by the Ethical Research Committee (ERC) of our institution and an official permission to carry out the study was obtained from the responsible authorities. Additionally, all potential hazards were explained to the participants and their families, and all participants gave their written informed consent before the start of the study.

All study participants were subjected to the following:

(A) History taking and clinical examination, including the age at onset of epilepsy, frequency of seizures per month, detailed description of ictal semiology with emphasis on the initial ictal manifestations, the pattern of seizure evolution and the associated ictal phenomena. The data were obtained from the patient and/or an eyewitness.

(B) Electroencephalography

The ictal video-EEG monitoring and inter-ictal scalp EEG studies were performed to localize the epileptogenic focus, via using a wireless 64-channel NihonKohden Neurofax and Medtronic-Dantic PL-270 EEG machines with an EEG cap, utilizing the international 10-20 electrode placement system [16]. All neurological and electro-clinical interpretations were carried out by a well-experienced neurologist (AA) with 24 years of experience in the field of epilepsy.

\section{(C) The MRI protocol}

All MRI sequences, including pulsed ASL-MRI (PASLMRI) and two-dimensional (2D) MV 1H-MRS techniques, were performed via using 1.5-Tesla MR unit (Signa Horizon SR 120; General Electric Medical Systems, Milwaukee, WI, USA) with 8-channel head coil, utilizing the commercially available corresponding 
software (Functool, HD version 15.0 M4A, GE Healthcare Medical Systems, Milwaukee, WI, USA).

\section{Structural MRI protocol}

Inter-ictal structural MRI protocol was achieved through using the sequences and parameters, which were mentioned in Table 1.

\section{Pulsed ASL-MRI protocol}

The 2D navigator-gated flow-alternating inversion recovery (FAIR) technique with repeated radiofrequency (RF) pulses and proper identification of the bolus length was used to obtain PASL-MRI in axial plane. An echoplaner imaging (EPI) sequence was used to gain a series of 50 paired labels/control PASL images, wherein blood was alternately tagged and untagged, via using single subtraction technique with the following parameters: field of view $(\mathrm{FOV})=24 \times 24$ square centimetres $\left(\mathrm{cm}^{2}\right)$; matrix $=64 \times 64$; repetition time/echo time $(\mathrm{TR} / \mathrm{TE})=$ $4225 / 10 \mathrm{~ms}$; flip angel $(\mathrm{FA})=180^{\circ}$; number of excitations $(\mathrm{NEX})=3$; readout $=8$ arms $\times 512$ samples; the voxel size $=3 \times 3 \times 5 \mathrm{~mm}^{3}$; and bandwidth $(\mathrm{BW})=62$,
$500 \mathrm{~Hz}$. The pulse labelling plane was placed just below the volume of interest, and the images were obtained by using labelling duration of 700-1500 ms, labelling thickness of $100 \mathrm{~mm}$ (with no inter-slice gap) and postlabelling delay (PLD) inversion time (TI) of $1500-2500$ $\mathrm{ms}$. The total acquisition time was 4 minutes and $22 \mathrm{~s}$.

The perfusion coloured maps of rCBF were automatically generated and superimposed on the 3D-FLAIR images to create multiplanar reconstruction images. The obtained data by PASL-MRI were analysed both qualitatively (by visual-based analysis) and quantitatively.

The qualitative visual-based analysis was interpreted with a colour scale ranging from blue (cool) to red (warm) colours. The area of abnormal perfusion, relative to the gray matter of the corresponding contralateral hemisphere and the remaining brain regions, was considered as an epileptogenic zone. Abnormal perfusion was either hypo-perfusion (with decreased $\mathrm{rCBF}$ ) or hyper-perfusion (with increased rCBF) [17].

Additionally, quantitative analysis was achieved using the workstation analysis package with commercially available software, where 3 regions of interest (ROIs) measured about $1.5 \times 1.5 \times 1 \mathrm{~cm}^{2}$ were manually allocated in the region with maximum perfusion

Table 1 Parameters of the used MRI sequences of the studied patients $(n=26)$

\begin{tabular}{|c|c|c|c|c|c|c|c|}
\hline $\begin{array}{l}\text { MRI } \\
\text { sequences }\end{array}$ & T1WTSE & T2WTSE & FLAIR & PDWTSE & T2*W-GRE & $\begin{array}{l}\text { DWI and } \\
\text { ADC }\end{array}$ & $\begin{array}{l}\text { Volumetric 3D } \\
\text { SPGR T1WI }\end{array}$ \\
\hline Type of scan & TSE & TSE & IR-TSE & TSE & GRE & $\begin{array}{l}\text { SENSE-SSh- } \\
\text { EPI + SPAIR }\end{array}$ & 3D SPGR \\
\hline Imaging plane & $\begin{array}{l}\text { Axial, sagittal } \\
\text { and coronal }\end{array}$ & $\begin{array}{l}\text { axial, sagittal and } \\
\text { oblique coronal }\end{array}$ & $\begin{array}{l}\text { axial, sagittal and } \\
\text { oblique coronal }\end{array}$ & $\begin{array}{l}\text { axial, sagittal and } \\
\text { oblique coronal }\end{array}$ & $\begin{array}{l}\text { Axial and } \\
\text { oblique } \\
\text { coronal }\end{array}$ & Axial & $\begin{array}{l}\text { Axial, sagittal } \\
\text { and coronal }\end{array}$ \\
\hline TR/TE (msec.) & $\begin{array}{l}400-460 / 4.6- \\
10\end{array}$ & $3000 / 80$ & $11000 / 120$ & $2000 / 20$ & $3500 / 30$ & $12000 / 82$ & $4264 / 70$ \\
\hline TI (msec.) & - & - & 2300 & - & - & - & - \\
\hline NEX & 2 & 3 & 1 & 1 & 2 & 2 & 1 \\
\hline FOV $\left(\mathrm{mm}^{3}\right)$ & $\begin{array}{l}200 \times 230 \times \\
150\end{array}$ & $220 \times 220 \times 150$ & $220 \times 220 \times 150$ & $220 \times 220 \times 150$ & $\begin{array}{l}220 \times 220 \times \\
150\end{array}$ & $\begin{array}{l}220 \times 220 \times \\
150\end{array}$ & $240 \times 240 \times 150$ \\
\hline $\mathrm{ST}(\mathrm{mm})$ & 3 & 3 & 2 & 2 & 2 & 1 & 1.5 \\
\hline Flip angle $\left(^{\circ}\right)$ & 20 & 20 & 90 & 90 & 90 & 90 & 90 \\
\hline $\begin{array}{l}b \text { value (s/ } \\
\mathrm{mm}^{2} \text { ) }\end{array}$ & 0 & 0 & 0 & 0 & 0 & $100-1000$ & 0 \\
\hline $\begin{array}{l}\text { Intersection } \\
\text { gap (mm) }\end{array}$ & 0 & 0 & 0 & 0 & 0 & 0 & 0 \\
\hline Matrix & $320 \times 320$ & $320 \times 320$ & $320 \times 320$ & $320 \times 320$ & $256 \times 256$ & $256 \times 256$ & $256 \times 256$ \\
\hline $\begin{array}{l}\text { Acquired voxel } \\
\text { size }\left(\mathrm{mm}^{3}\right)\end{array}$ & $\begin{array}{l}1.00 \times 1.26 \times \\
3.0\end{array}$ & $1.00 \times 1.42 \times 3.0$ & $0.75 \times 0.81 \times 5$ & $0.75 \times 0.81 \times 5$ & $\begin{array}{l}0.9 \times 1.52 \times \\
5.0\end{array}$ & $\begin{array}{l}1.49 \times 1.50 \\
\times 3.0\end{array}$ & $0.75 \times 0.81 \times 5$ \\
\hline $\begin{array}{l}\text { Scan time } \\
\text { (min) }\end{array}$ & $5-6$ & $6-7$ & $6-7$ & $6-7$ & $6-7$ & $6-7$ & $6-7$ \\
\hline
\end{tabular}

T1W T1-weighted, T2W T2-weighted, TSE turbo spin-echo, min minutes, T1WTSE T1-weighted turbo spin-echo, T2WFSE T2-weighted fast spin-echo, FLAIR fluid attenuation inversion recovery, IR-TSE inversion recovery-turbo spin echo, PDWTSE proton density-weighted turbo spin echo, 3D SPGR TIWI three-dimensional spoiled gradient echo T1WI, T2*-GRE T2*-weighted gradient recalled echo, DWI diffusion-weighted image, SENSE-SSh-EPI sensitivity encoding single shot-echo planar imaging, STIR short tau inversion recovery, TR/TE repetition time/echo time, $\mathrm{mm}^{3}$ cubic millimetres, msec milliseconds, NEX number of excitations, FOV field of view, $\left(^{\circ}\right)$ degrees, $s / \mathrm{mm}^{2}$ seconds/square millimetres, $\mathrm{mm}$ millimetres, min minutes, ST slice thickness 
abnormality, which was considered as an epileptogenic zone, and similar ROIs were symmetrically placed in the corresponding contra-lateral region. The rCBF was estimated in millilitre per $100 \mathrm{~g}$ of brain tissue per minute $(\mathrm{ml} / 100 \mathrm{~g} / \mathrm{min})$, in all selected ROIs with calculation of arterial spin-labelled asymmetry index percent; ASLAI (\%) according to the following equation [18]:

$$
\begin{aligned}
\operatorname{ASLAI}(\%)= & \frac{2 \times(\text { Ipsilateral }- \text { Contralateral })}{\text { Ipsilateral }+ \text { Contralateral }} \\
& \times 100 \%
\end{aligned}
$$

\section{The MV 1H-MRS protocol}

In all studied patients, the MV $1 \mathrm{H}-\mathrm{MRS}$ was achieved via using SE mode with $2 \mathrm{D}$ spin-echo point-resolved spectroscopy sequence (PRESS) technique with twophase encoding gradients. The MRS scan was initiated if the line width reported by the pre-scan process was less than $8 \mathrm{~Hz}$ and the following parameters were used: TR $=1700 \mathrm{~ms}$; long TE of $144 \mathrm{~ms}$ and additional short TE of $35 \mathrm{~ms}$ was added to detect signals from myo-inositol (MI) and the sum of glutamate and glutamine (Glu + Gln = Glx) metabolite peaks; FOV $=24 \times 24 \mathrm{~cm}^{2}$, phase encoding matrix $=18 \times 18, \mathrm{ST}=1.5 \mathrm{~cm}$, spectral width of $2500 \mathrm{~Hz}$ and data points of 2048 with the total acquisition time was $10 \mathrm{~min}$ and $54 \mathrm{~s}$.

At the voxel level, shimming was initially achieved automatically then manually on the water resonance and the spectra were obtained with optimal water resonance suppression via using chemical shift-selective suppression (CHESS) pulses, while lipid resonance suppression was achieved by using a section-selective inversion pulse (SSIP), with an TI $=305 \mathrm{~ms}$. The obtained spectra were displayed as grids of localized voxels of interest (VOIs) with nominal size of $80 \times 80 \times 15 \mathrm{~mm}^{3}$, which were overlaid on the conventional MR images (T2WI or FLAI $R$ sequences in sagittal, axial, and coronal orientations, which were covering the whole brain). The VOIs were bilaterally distributed in regions of abnormal perfusion, which were visually identified by PASL-MRI, as well as in their corresponding areas on the contra-lateral hemispheres for comparison, in addition to the thalamus, basal ganglia and cerebellum, bilaterally.

The off-line spectral post-processing was carried out by using the workstation spectroscopic analysis package with commercially available software. The main metabolite resonances were limited to $2.02 \mathrm{ppm}$ for $\mathrm{N}$-acetylaspartate (NAA), $3.02 \mathrm{ppm}$ for creatine $(\mathrm{Cr}), 3.20 \mathrm{ppm}$ for choline (Cho), 2.4 ppm for Glx, 1.3-1.4 ppm for lactate (Lac) doublet and $3.56 \mathrm{ppm}$ for MI. As a result of difficulties in the calculation of the absolute metabolite concentrations; their relative concentration ratios were quantitatively assessed by using the method of relative quantification. The relative concentrations ratios of NAA/Cr, NAA/Cho, NAA/(Cho + Cr), MI/NAA, Glx/ NAA and $\mathrm{Glx} / \mathrm{Cr}$ ratios were taken as analysis indices. They were bilaterally measured in all symmetrical pairs of selected VOIs. For each peak metabolite concentration ratio of right-left voxel pairs of each cerebral region, the percent asymmetry factor (\% AF) for lateralization was calculated, from the following equation, where the lateralization was always towards the side with the lower value [19]:

$$
\% \mathrm{AF}=\frac{2 \times(\text { Ipsilateral }- \text { Contralateral })}{\text { Ipsilateral }+ \text { Contralateral }} \times 100 \%
$$

Interpretation of imaging procedures were carried out by a team of two experienced neuro-radiologists (RE and RM), with 18 and 8 years of experience in the field of neuroradiology. They were blinded to the EEG results and there was no intra-or interobserver variability as the two neuro-radiologists, who were the authors, reviewed the images together with consensus.

\section{Statistical analysis}

The SPSS for Windows version 20.0 software package (SPSS Inc, Chicago, IL) was used for statistical data analysis. The $P$ value below $0.05(P<0.05)$ was considered statistically significant. Additionally, the receiver operating characteristic (ROC) curve analysis was used to determine the optimal cut-off values and maximal area under curve (AUC) with evaluation of the diagnostic accuracy, sensitivity, specificity, positive and negative predictive values (PPV and NPV, respectively) of PASL-MRI and MV 1H-MRS of brain in localization and lateralization of epileptogenic zones.

\section{Results}

The current study included 26 consecutive patients with focal impaired awareness epilepsy. The age of the studied patients ranged from 16 to 57 years with the mean age of $26.56 \pm 4.64$ years, while the mean age at first onset of epilepsy was $9.95 \pm 3.74$ years. Results of other related clinical features were shown in Table 2.

As shown in Table 3, the visual-based analysis of PASL-MRI demonstrated only one case, of right temporal lobe epilepsy, with apparently normal perfusion (non-localized and non-lateralized) that was considered as a false negative result (Fig. 1). On the other hand, the visual-based analysis of PASL-MRI revealed that in most of the studied patients $(19 / 26 ; 73.08 \%)$ the putative zones of epileptogenic activity with abnormal perfusion were detected in the temporal region. These epileptogenic zones were well-lateralized and well-localized in 
Table 2 Demographic and clinical data of the study participants

\begin{tabular}{|c|c|c|c|c|c|}
\hline \multicolumn{4}{|l|}{$\underline{\text { Data }}$} & & Patients $(n=26)$ \\
\hline \multirow{2}{*}{\multicolumn{4}{|c|}{ Gender }} & Females & $14(53.85 \%)$ \\
\hline & & & & Males & $12(46.15 \%)$ \\
\hline \multirow{2}{*}{\multicolumn{4}{|c|}{ Age in years }} & Range & $16-57$ \\
\hline & & & & Mean \pm SD & $26.56 \pm 4.64$ \\
\hline \multirow{2}{*}{\multicolumn{4}{|c|}{ Age at first onset of epilepsy }} & Range & $6.98-15.87$ \\
\hline & & & & Mean \pm SD & $9.95 \pm 3.74$ \\
\hline \multirow{2}{*}{\multicolumn{4}{|c|}{ Family history for epilepsy }} & Negative; $n$ (\%) & $16(61.53 \%)$ \\
\hline & & & & Positive; $n$ (\%) & $10(38.47 \%)$ \\
\hline \multirow{2}{*}{\multicolumn{4}{|c|}{ Duration of epilepsy in years }} & Range & $8.56-20.75$ \\
\hline & & & & Mean \pm SD & $14.70 \pm 6.58$ \\
\hline \multirow{2}{*}{\multicolumn{4}{|c|}{ Frequency of attacks / month }} & Range & $4.75-14.22$ \\
\hline & & & & Mean \pm SD & $6.50 \pm 0.72$ \\
\hline \multirow[t]{6}{*}{ Clinical and EEG results } & Laterality of the epileptic activity & \multicolumn{2}{|c|}{ Left sided lateralization } & $n(\%)$ & $14(53.84 \%)$ \\
\hline & & \multicolumn{2}{|c|}{ Right sided lateralization } & $n(\%)$ & $12(46.16 \%)$ \\
\hline & Localization of the epileptic activity & \multicolumn{2}{|l|}{ Temporal } & $n(\%)$ & $19(73.09 \%)$ \\
\hline & & Extra-temporal & Frontal & $n(\%)$ & $5(19.21 \%)$ \\
\hline & & & Parietal & $n(\%)$ & $1(3.85 \%)$ \\
\hline & & & Occipital & $n(\%)$ & $1(3.85 \%)$ \\
\hline
\end{tabular}

Statistical data were expressed as number (n), percent (\%) and mean \pm standard deviation (SD), EEG electroencephalography

most of the studied patients $(21 / 26 ; 80.77 \%)$. They appeared as ipsilateral regions of abnormal perfusions, either hypoperfusion with decreased $\mathrm{rCBF}(19 / 26 ; 73.08 \%)$ (Fig. 2) or hyperperfusion with increased $\mathrm{rCBF}(2 / 26$; $7.68 \%$ ), which displayed cool and warm colours, respectively, according to the colour scale of the coloured perfusion maps. However, false localization of the epileptic zone was observed in $2(7.68 \%)$ patients with temporal lobe epilepsy (Figs. 3 and 4) and false lateralization was also observed in another $2(7.68 \%)$ patients with temporal lobe epilepsy in one patient and parietal lobe epilepsy in the other patient (Figs. 5 and 6). Moreover, we assessed the diagnostic performance of the visual-based analysis of PASL-MRI data obtained from the generated coloured maps, and revealed sensitivity $90.48 \%$, specificity $87.10 \%$ and accuracy $88.46 \%$.

As shown in Table 4, the mean rCBF in the zone of epileptogenic activity was significantly lower than that of the corresponding regions of the contralateral hemisphere $(P<0.001)$ with the mean ASLAI\% was $18.65 \pm$ $10.12 \%$. Also, the mean $\mathrm{rCBF}$ of the thalamus ipsilateral to the assumed epileptogenic zone was significantly lower than that of the contralateral hemisphere $(P=$ 0.023 ) with the mean ASLAI\% was $9.23 \pm 1.17 \%$. On the other hand, we did not find significant differences in the mean $\mathrm{rCBF}$ in the basal ganglia, cerebellum and apparently normal brain tissue on the ipsilateral hemisphere when compared to the corresponding regions of the contralateral hemisphere $(P=0.183, P=0.279, P=$
0.456 and $P=0.568$; respectively), with the mean ASLA $\mathrm{I} \%$ was $6.88 \pm 1.22 \%, 2.2 \pm 1.4 \%$ and $1.1 \pm 0.09 \%$; respectively.

As seen in Table 5, the means of NAA/Cho, NAA/Cr and NAA/ $(\mathrm{Cho}+\mathrm{Cr})$ peak ratios were significantly reduced $(P<0.02, P=0.01$ and $P<0.001$, respectively), while each of the MI/NAA, Glx/NAA and Glx/Cr was significantly increased $(P=0.044, P<0.001$ and $P<$ 0.018 ; respectively) in the suggested zones of epileptogenic activity, when compared to the corresponding regions without epileptogenic activity on the contra-lateral hemisphere. On the other hand, areas of seizure spread on the ipsilateral side showed no significant differences among all of the studied metabolites peak concentration ratios when compared to their levels on the contralateral side $(P>0.05)$, except MI/NAA which was significantly decreased on the ipsilateral side $(P<0.01)$. Furthermore, we observed a significant reduction in the NAA/(Cho + Cr) $(P<0.01)$ and significant increase in the Glx/NAA $(P<0.02)$ in the ipsilateral thalamus compared to the contralateral thalamus in $3(11.53 \%)$ patients, while the same changes were detected in the contralateral thalamus in only one $(3.85 \%)$ patient. On the other hand, we found no significant difference in the mean metabolite ratios in the basal ganglia and cerebellum bilaterally $(P>$ 0.05).

Table 6 demonstrated that most of the studied patients $(25 / 26 ; 96.15 \%)$ showed significantly increased mean \%AF for all estimated peak metabolites concentration 
Table 3 Diagnostic performance of qualitative (visual) data of ASL-MRI of both cerebral hemispheres $(n=52)$ of the studied patients $(n=26)$

\begin{tabular}{|c|c|c|c|c|c|c|c|}
\hline \multicolumn{2}{|c|}{ Inter-ictal visual qualitative analysis PASL-MRI results } & \multicolumn{4}{|c|}{$\begin{array}{l}\text { Region of abnormal } \\
\text { perfusion }\end{array}$} & \multirow{2}{*}{\multicolumn{2}{|c|}{ Total }} \\
\hline & & \multicolumn{2}{|c|}{ Temporal } & \multicolumn{2}{|c|}{$\begin{array}{l}\text { Extra- } \\
\text { temporal }\end{array}$} & & \\
\hline & & No & $\%$ & No & $\%$ & No & $\%$ \\
\hline Non-localization and non-lateralization & & 1 & $3.85 \%$ & 0 & $0 \%$ & 1 & $3.85 \%$ \\
\hline \multirow[t]{3}{*}{ Well-localized and well-lateralized $(21 ; 80.77 \%)$} & Isolated ipsilateral focal hypoperfusion & 14 & $53.84 \%$ & 4 & $15.38 \%$ & 18 & $69.22 \%$ \\
\hline & Isolated ipsilateral focal hyperperfusion & 1 & $3.85 \%$ & 1 & $3.85 \%$ & 2 & $7.68 \%$ \\
\hline & $\begin{array}{l}\text { Ipsilateral hypoperfusion (epileptogenic focus) with hypopefusion } \\
\text { of the ipsilateral thalamus }\end{array}$ & 0 & $0 \%$ & 1 & $7.68 \%$ & 1 & $3.85 \%$ \\
\hline \multirow[t]{2}{*}{ False-localization (2; 7.68\%) } & $\begin{array}{l}\text { Ipsilateral focal hypoperfusion of multiple cerebral lobes of the } \\
\text { epileptogenic hemisphere including the epileptogenic irritative } \\
\text { zone and associated ipsilateral cerebral areas of seizure spread, } \\
\text { and focal hypopefusion of the ipsilateral thalamus }\end{array}$ & 1 & $3.85 \%$ & 0 & $0 \%$ & 1 & $3.85 \%$ \\
\hline & $\begin{array}{l}\text { Ipsilateral focal hypoperfusion of multiple cerebral lobes of the } \\
\text { epileptogenic hemisphere including the epileptogenic irritative } \\
\text { zone and associated ipsilateral cerebral areas of seizure spread }\end{array}$ & 1 & $3.85 \%$ & 0 & $0 \%$ & 1 & $3.85 \%$ \\
\hline \multirow[t]{2}{*}{ False-lateralization (2; 7.68\%) } & $\begin{array}{l}\text { Ipsilateral hypoperfusion (epileptogenic focus) with hypopefusion } \\
\text { of the contra-lateral lobes and/or contra-lateral thalamus }\end{array}$ & 1 & $3.85 \%$ & 0 & $0 \%$ & 1 & $3.85 \%$ \\
\hline & $\begin{array}{l}\text { Ipsilateral focal hypoperfusion (epileptogenic focus) with focal } \\
\text { hypoperfusion of the corresponding contralateral homologous } \\
\text { (mirror focus) }\end{array}$ & 0 & $0 \%$ & 1 & $3.85 \%$ & 1 & $3.85 \%$ \\
\hline Total & & 19 & $73.08 \%$ & 7 & $26.92 \%$ & 26 & $100 \%$ \\
\hline \multicolumn{8}{|c|}{ Sensitivity, specificity, PPV, NPV and accuracy of visual analysis of PASL-MRI results in the inter-ictal state } \\
\hline Sensitivity \% & Specificity \% & \multicolumn{2}{|c|}{ NPV \% } & \multicolumn{2}{|c|}{ Accuracy \% } & & \\
\hline 90.48 & $82.61 \%$ & \multicolumn{2}{|c|}{$93.10 \%$} & \multicolumn{2}{|c|}{$88.46 \%$} & & \\
\hline
\end{tabular}

PASL-MRI pulsed arterial spin labelled MRI, PPV positive predictive value, NPV negative predictive value.

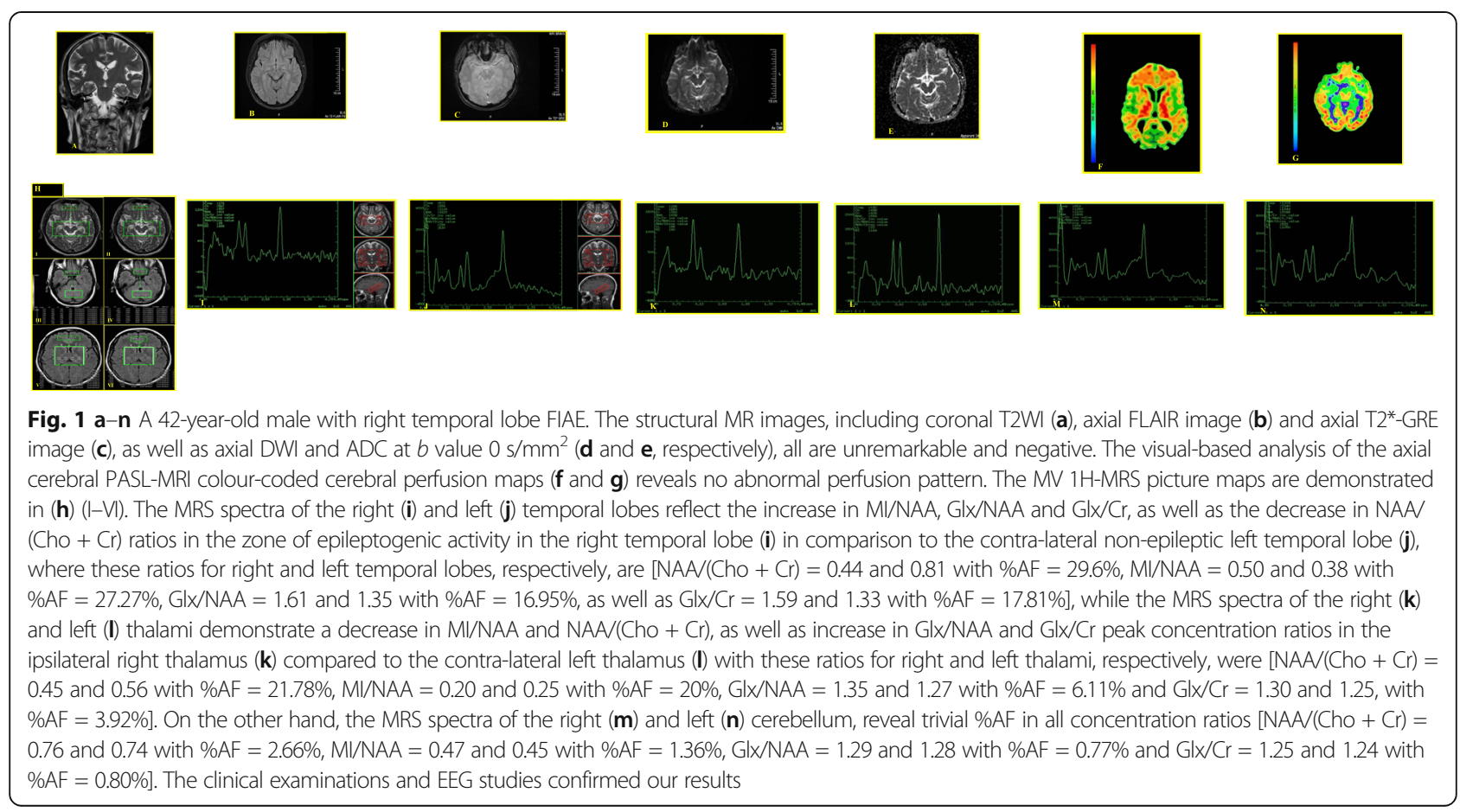



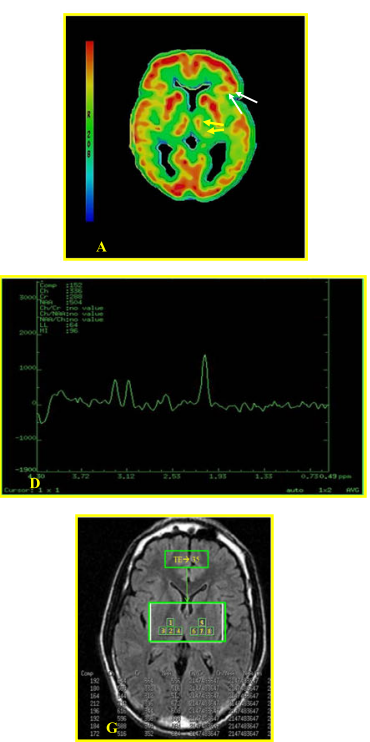
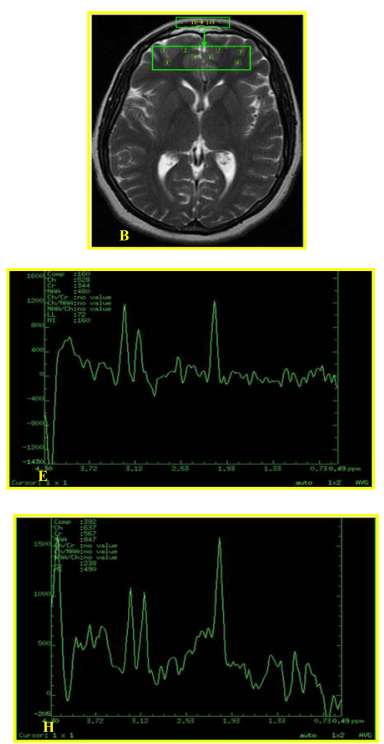
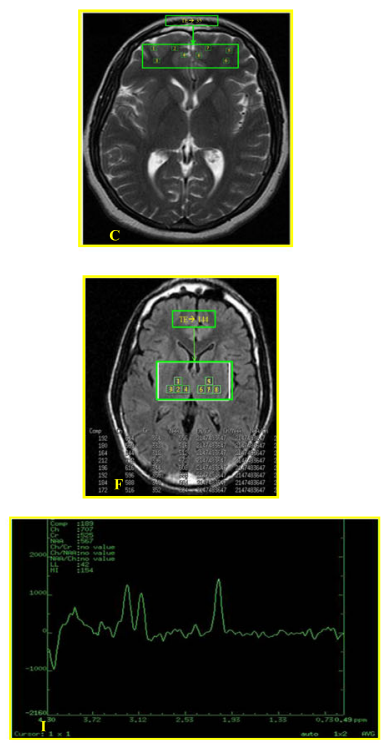

Fig. 2 a-i A 33-year-old female patient of non-lesional left frontal lobe FIAE The visual-based analysis of the axial PASL-MRI colour-coded cerebral perfusion map (a) demonstrates a focal hypoperfusion of the left frontal lobe (white arrows) and ipsilateral thalamus (yellow arrows). The estimated rCBF for right and left frontal lobes was 76.25 and $62.67 \mathrm{ml} / 100 \mathrm{~g} / \mathrm{min}$, respectively, with the calculated ASLAI\% of $14.91 \%$. Additionally, the estimated rCBF of the right and left thalami was 74.77 and $69.09 \mathrm{ml} / 100 \mathrm{~g} / \mathrm{min}$, respectively, with the calculated ASLAl\% of $8.90 \%$. The MV $1 \mathrm{H}-\mathrm{MRS}$ picture maps of both frontal lobes and thalami, were obtained at a long TE of $144 \mathrm{~ms}$ ( $\mathbf{b}$ and $\mathbf{f}$, respectively) and at a short TE of $35 \mathrm{~ms}$ (c and $\mathbf{g}$, respectively). The MRS spectra demonstrate increased MI/NAA, GIX/NAA and GIx/Cr, as well as decreased NAA/(Cho $+\mathrm{Cr}$ ) ratios in the left frontal lobe (e) compared to the right frontal lobe (d), while the ipsilateral left thalamus (i), when compared to the contra-lateral right thalamus (h), showed decreased MI/NAA and NAA/(Cho $+\mathrm{Cr}$ ), as well as increased GIx/NAA and Glx/Cr ratios. For right and left frontal lobes, these ratios were $[\mathrm{NAA} /(\mathrm{Cho}+\mathrm{Cr})=0.80$ and 0.55 with \%AF of 38.24\%, MI/NAA $=0.20$ and 1.27 with \%AF of $14.56 \%, \mathrm{Gl} / \mathrm{NAA}=1.33$ and 1.58 with \%AF of $17.18 \%$ and $\mathrm{Gl} / \mathrm{Cr}=1.30$ and 1.53 with \%AF of 16.25\%]. These ratios for right and left thalami, respectively, are [NAA/(Cho $+\mathrm{Cr})=$ 0.60 and 0.46 with \%AF of $26.42 \%, \mathrm{MI} / \mathrm{NAA}=0.38$ and 0.27 with \%AF of $33.85 \%, \mathrm{Gl} / \mathrm{NAA}=1.28$ and 1.49 with \%AF of $15.16 \%$ and $\mathrm{Gl} / \mathrm{Cr}=1.25$ and 1.45 , with \%AF of $14.81 \%]$

ratios including NAA/Cho, NAA/Cr, NAA/(Cho $+\mathrm{Cr})$, MI/NAA, Glx/NAA and Glx/Cr ratios $(P<0.001, P<$ $0.002, P<0.001, P=0.01, P=0.02$ and $P=0.03$ respectively). Only one case (3.85\%) showed trivial and inconsiderable \%AF.

By analysing the results of the ROC curves of PASLMRI and MV 1H-MRS in all patients, as shown in Table 7 and Fig. 7, we utilized a cut-off value $\geq 5.96 \%$ and AUC of 0.968 for increased ASLAI\% (with $96.01 \%$ sensitivity, $91.70 \%$ specificity and $95.78 \%$ accuracy) and a cutoff value $\leq 64.87$ and AUC of 0.957 for reduced $\mathrm{rCBF}$ (with $98.31 \%$ sensitivity, $92.90 \%$ specificity and $94.75 \%$ accuracy), for proper localization and lateralization of the epileptogenic zone. Additionally, we found that the increased mean \%AF at a cut-off value $\geq 9.98 \%$ with AUC of 0.983 (100\% sensitivity, $97.65 \%$ specificity and 98.14\% accuracy), MI/NAA ratio at a cut-off value $\geq 0.98$ with AUC of 0.989 (100\% sensitivity, $96.34 \%$ specificity and $97.86 \%$ accuracy) and Glx/NAA ratio at a cut-off value $\geq 1.55$ with AUC of 0.972 (100\% sensitivity, 96.35\% specificity and $97.24 \%$ accuracy), as well as decreased $\mathrm{NAA} /(\mathrm{Cho}+\mathrm{Cr})$ ratio at a cut-off value $\leq 0.59$ with AUC of 0.977 (100\% sensitivity, $96.9 \%$ specificity and 97.74\% accuracy) facilitated adequate identification of the epileptogenic zone. Furthermore, the combined use of PASL-MRI and multi-voxel 1H-MRS enabled accurate localization and lateralization of the epileptogenic zone in patients with FIAE (100\% sensitivity, $98.45 \%$ specificity and $98.86 \%$ accuracy).

\section{Discussion}

The proper identification of an epileptic focus is a vital diagnostic challenge particularly in non-lesional epilepsy [20]. Although scalp EEG and video-EEG monitoring are the most common methods used for focus localization, the data given by them are limited [21]. Conventional MRI remains the method of choice for identification of the gross structural brain lesions. However, normal MRI findings are observed in about $30 \%$ of patients with FIAE of temporal lobe origin [20]. Epilepsy is ultimately a disease of brain function, in which seizures are accompanied by alterations of rCBF and cerebral metabolism [21].

The PASL-MRI is a promising, non-invasive and nongadolinium-dependent perfusion-based MRI acquisition, which facilitates quantitative estimation of the $\mathrm{rCBF}$ and provides serial imaging with greater accessibility than SPECT or PET techniques and without radiation exposure or contrast media [11]. 

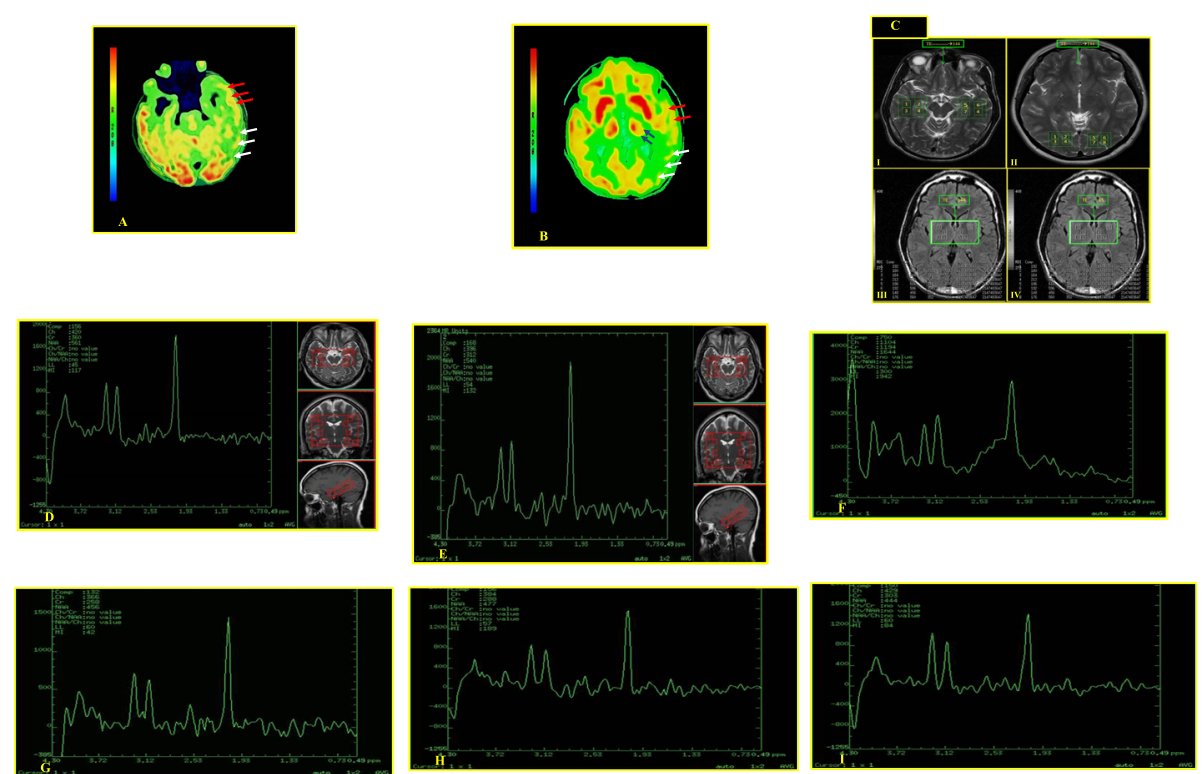

Fig. 3 a-i A 40-year-old male patient with non-lesional left temporal lobe FIAE. The visual-based analysis of the axial PASL-MRI colour-coded cerebral perfusion maps (a and $\mathbf{b}$ ) reveals a focal hypoperfusion of the epileptogenic left temporal lobe (red arrows), the ipsilateral occipital lobe that represents the area of seizure spread (white arrows) and the ipsilateral thalamus (blue arrows). The estimated rCBF for the right and left temporal lobes was 69.78 and $50.03 \mathrm{ml} / 100 \mathrm{~g} / \mathrm{min}$, respectively, with ASLAl\% of 32.97\%, as well as that of the right and left occipital lobes was 71.22 and $66.82 \mathrm{ml} / 100 \mathrm{~g} / \mathrm{min}$., respectively, with ASLAl\% of 6.37\%, while the estimated rCBF of the right and left thalami was $68.89 \mathrm{and} 62.19 \mathrm{ml}$ $100 \mathrm{~g} / \mathrm{min}$, respectively, with ASLAI\% of 9.50\%. The MV 1H-MRS picture maps illustrating the studied ROls in (c) (I-IV). The MRS spectra of the right and left temporal lobes ( $\mathbf{d}$ and $\mathbf{e}$, respectively), as well as the right and left occipital lobes ( $\mathbf{f}$ and $\mathbf{g}$, respectively), in addition to the right and left thalami ( $h$ and $\mathbf{i}$, respectively), demonstrated increased MI/NAA, Glx/NAA and Glx/Cr, as well as decreased NAA/(Cho $+\mathrm{Cr}$ ) ratios in the zone of epileptogenic activity in the left temporal lobe (e) in comparison to the contra-lateral temporal lobe (d), while the ipsilateral left occipital lobe (g) and the ipsilateral thalamus (i) showed decreased MI/NAA and NAA/(Cho $+\mathrm{Cr}$ ), as well as increased Glx/NAA and Glx/Cr ratios, when compared to their corresponding contra-lateral regions. For the right and left temporal lobes, these ratios were [NAA/(Cho $+\mathrm{Cr})=0.72$ and 0.65 with \%AF of $10.22 \%, \mathrm{MI} / \mathrm{NAA}=0.21$ and 1.07 with \%AF of $13.44 \%$, GIX/NAA $=1.25$ and 1.61 with $\% \mathrm{AF}$ of $25.17 \%$ and $\mathrm{Gl} / \mathrm{Cr}=1.22$ and 1.50 with \%AF of 20.58\%]. For the right and left occipital lobes, these ratios were [NAA/(Cho $+\mathrm{Cr})=0.72$ and 0.67 ; with \%AF of 7.25\%, MI/NAA $=0.38$ and 0.27 with; \%AF of $72.13 \%$, GIX/NAA $=1.33$ and 1.65 with \%AF of $21.48 \%$ and $\mathrm{GlX} / \mathrm{Cr}=1.30$ and 1.59, with \%AF of 20.07\%]. For the right and left thalami, these ratios were $[\mathrm{NAA} /(\mathrm{Cho}+\mathrm{Cr})=0.71$ and 0.61 with \%AF of $15.15 \%, \mathrm{MI} / \mathrm{NAA}=0.40$ and 0.19 with \%AF of $71.18 \%, \mathrm{Gl} / \mathrm{NAA}=1.31$ and 1.57 with \%AF of $18.06 \%$ and $\mathrm{Glx} / \mathrm{Cr}=1.29$ and 1.54 , with \%AF of $17.67 \%]$

The study in hand goes parallel with the observations of previous studies $[1,22,23]$ and revealed that the temporal lobe is the commonest affected lobe with FIAE, while most of patients with extra-temporal lobe FIAE have frontal lobe epilepsy.

The visual-based analysis of PASL-MRI identified the epileptogenic zones with well-lateralization and welllocalization in most of the studied patients (21/26; $80.77 \%$ ). As reported by other previous studies [7, 2426], the epileptogenic zones appeared as ipsilateral regions of abnormal perfusions, either hypo-perfusion with decreased rCBF $(19 / 21 ; 90.48 \%)$ or hyper-perfusion with increased $\mathrm{rCBF}(2 / 21 ; 9.52 \%)$, which displayed cool and warm colours, respectively, according to the colour scale of the perfusion maps. Actually, the definite pathological mechanism of the inter-ictal focal hypo-perfusion of the epileptogenic zone with irritative focus is not yet clear. It could be attributed to cortical atrophy, gliosis, reduced synaptic density and/or neural loss in the epileptogenic zone [27]. However, a possible positive linear correlation between the inter-ictal perfusion of the epileptogenic zone and the frequency of the inter-ictal epileptic activity might exist to explain the interictal hyperperfusion in epileptogenic zones [28].

Moreover, the visual-based analysis of PASL-MRI data of the current study demonstrated false localization of the epileptogenic zone in 2 patients $(2 / 26 ; 7.69 \%)$ with temporal non-lesional FIAE (Figs. 3 and 4) and false lateralization in 2 other patients $(2 / 26 ; 7.68 \%)$ with parietal and temporal lobe FIAE (Figs. 5 and 6). In all of them, there was hypoperfusion with cool colour in the focal epileptogenic zones as well as in areas of seizure spread, which can be attributed to the rapid seizure spread or sub-clinical seizure onset [23].

Noteworthy, this visual-based analysis yielded $90.48 \%$ sensitivity, $87.10 \%$ specificity and $88.46 \%$ accuracy in proper identification of the epileptogenic foci. However, Kim et al. [11] reported a diagnostic ability of the interictal visual analysis of PASL-MRI in patients with nonlesional FIAE of $74 \%$ sensitivity, $0 \%$ specificity and $70 \%$ 

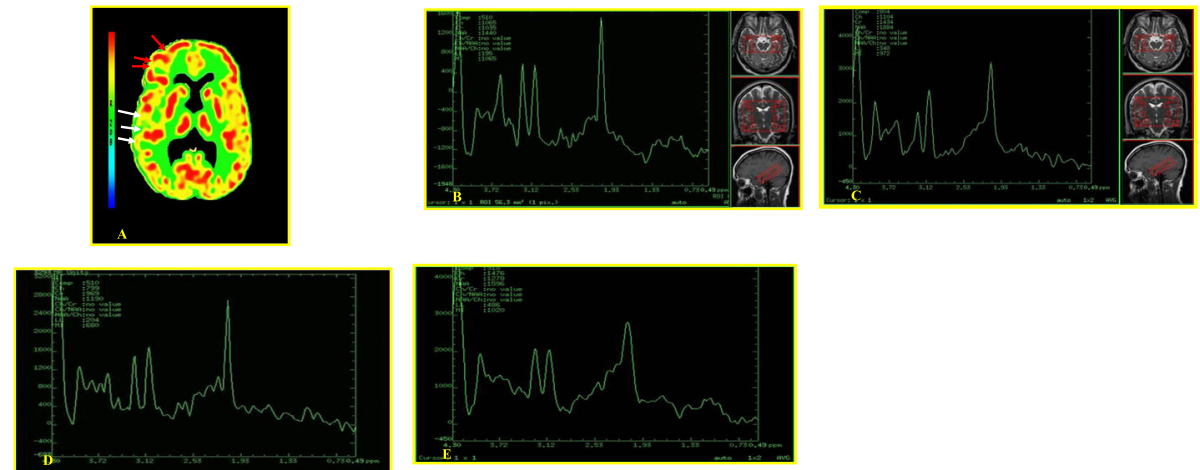

Fig. 4 a-e A 22-year-old male patient with non-lesional right temporal lobe FIAE. The visual-based analysis of the axial PASL-MRI colour-coded cerebral perfusion map (a) highlights the hypoperfusion of the epileptogenic right temporal lobe (white arrows) associated with focal hypoperfusion of the ipsilateral right frontal lobe, which represented the cerebral area of seizure spread (red arrows). The estimated rCBF for the right and left temporal lobes was 52.34 and $70.98 \mathrm{ml} / 100 \mathrm{~g} / \mathrm{min}$, respectively, with ASLAl\% of $30.23 \%$. Additionally, the estimated rCBF of the right and left frontal lobes was 68.92 and $75.88 \mathrm{ml} / 100 \mathrm{~g} / \mathrm{min}$, respectively, with ASLAl\% of 9.61\%. The MV $1 \mathrm{H}-\mathrm{MRS}$ spectra of the right and left temporal lobes (b and $\mathbf{c}$, respectively), demonstrated increased MI/NAA, GIx/NAA and GIx/Cr, as well as decreased NAA/(Cho $+\mathrm{Cr}$ ) ratios in the zone of epileptogenic activity in the right temporal lobe (b) in comparison to the contra-lateral non-epileptogenic left temporal lobe (c). For the right and left temporal lobes (b and c, respectively), these ratios were $[\mathrm{NAA} /(\mathrm{Cho}+\mathrm{Cr}$ ) $=0.54$ and 0.74 with \%AF of 31.25\%, MI/NAA $=0.74$ and 0.52 with \%AF of $34.92 \%$, GIX/NAA $=1.60$ and 1.45 with \%AF of $9.84 \%$ and $\mathrm{Gl} / \mathrm{Cr}=1.53$ and 1.40 with \%AF of 8.87\%]. On the other hand, the ipsilateral right frontal lobe (d), which represented the cerebral area of seizure spread, showed decreased MI/NAA and NAA/(Cho + Cr), as well as increased GIx/NAA and GIx/Cr ratios, when compared to the contra-lateral left frontal lobe (e), where these ratios, for right and left frontal lobes, respectively, were $[\mathrm{NAA} /(\mathrm{Cho}+\mathrm{Cr})=0.67$ and 0.88 with \%AF of $27.09 \%, \mathrm{MI} / \mathrm{NAA}=0.57$ and 0.64 with \%AF of $11.57 \%$, Glx/NAA $=1.39$ and 1.30 with \%AF of $6.69 \%$ and $\mathrm{Gl} / \mathrm{Cr}=1.34$ and 1.25 , with \%AF of $6.95 \%]$

accuracy. These variations might be attributed to differences in the duration of epilepsy, variations in labelling techniques and different post-processing methods. In fact, the visual-based analysis is inefficient in detecting slight changes in the rCBF, which are vulnerable to subjective factors of the observers that significantly influence its diagnostic performance [26].

Therefore, to improve the diagnostic performance of PASL-MRI, we calculated the ASLAI\% and found that the significant increase in the ASLAI\% (at cut-off value $\geq 5.96 \%$ and AUC of 0.968 with $96.01 \%$ sensitivity, $91.70 \%$ specificity and $95.78 \%$ accuracy) and reduced rCBF (at cut-off value $\leq 64.87$ and AUC of 0.957 with 98.31\% sensitivity, $92.90 \%$ specificity and $94.75 \%$ accuracy), facilitated proper localization and lateralization of the epileptogenic zone. Parallel to our results, Eryurt et al. [29] utilized a cut-off value 0.89 for reduced rCBF and a cut-off value 5.8\% for increased ASLAI\% with 71\% sensitivity and $78 \%$ specificity. On the contrary, Guo et al. [30] used a cut-off value $4.0 \%$ for significant hippocampal ASLAI\% increase (with $80.8 \%$ sensitivity and $72.7 \%$ specificity), while they used a cut-off value $4.5 \%$ for amygdala (with $65.4 \%$ sensitivity and $77.3 \%$ specificity). However, they reported significant reduction in the rCBF ipsilateral in the epileptogenic temporal lobe, compared to the contra-lateral non-epileptic temporal lobe and control, with significant increase in the ASLAI\%. These differences might be attributed to differences in the region of seizure, post-processing technique and statistical methods.

The $1 \mathrm{H}$-MRS can be considered as an in-vivo metabolic biopsy, which has the potential to provide data about neurochemical changes in a selected volume of the brain that may precede the development of structural lesions particularly in patients with negative MRI. This can be achieved by quantification of the endogenous cerebral metabolites including NAA (a marker for neuronal status and integrity with its reduction is interpreted as mitochondrial metabolism dysfunction or neuronal loss), Cho (a marker for membrane integrity and turnover), $\mathrm{Cr}$ (a marker for energy metabolism), MI (a marker for glial cell integrity) and Glx (is an excitatory neurotransmitter, which plays a role in mitochondrial metabolism and can serve as a marker of epileptic networks) [20,31].

In accordance with previous studies $[1,32,33]$, we observed a significant reduction in the mean peak ratios of $\mathrm{NAA} / \mathrm{Cho}, \mathrm{NAA} / \mathrm{Cr}$ and NAA/ $/ \mathrm{Cho}+\mathrm{Cr})(P<0.02, P=$ 0.01 and $P<0.001$, respectively), in the proposed zone of focal epileptogenic activity when compared to the homologous region of the contra-lateral nonepileptogenic region. However, Zhang et al. [20] and Davis et al. [34] stated that, in patients with temporal lobe epilepsy, NAA/(Cho $+\mathrm{Cr})$ value ipsilateral to the EEG epileptogenic focus was not significantly lower than that of the corresponding contralateral regions. 

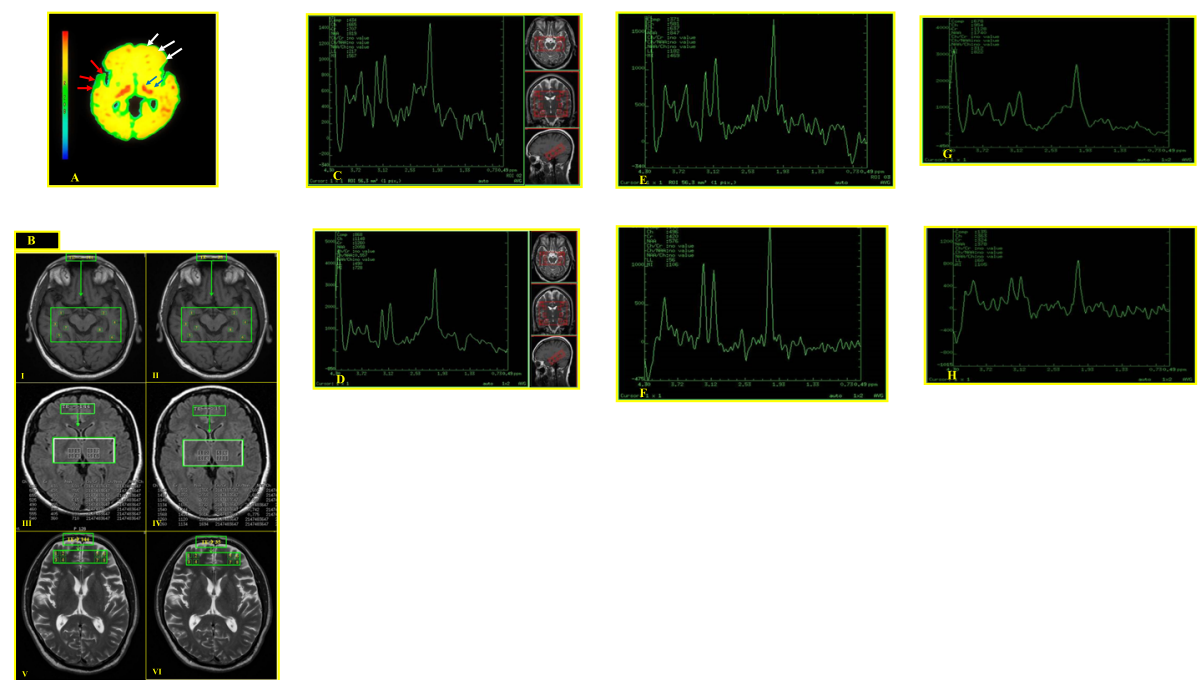

Fig. 5 a-h A 27-year-old male patient with non-lesional right temporal lobe FIAE. The visual-based analysis of the axial PASL-MRI colour-coded cerebral perfusion map (a) reflects the hypoperfusion of the epileptogenic right temporal lobe (red arrows) and the contra-lateral right frontal lobe, which represented the cerebral area of seizure spread (white arrows) and the contra-lateral left thalamus (blue arrows). The estimated rCBF for the right and left temporal lobes was 49.76 and $67.98 \mathrm{ml} / 100 \mathrm{~g} / \mathrm{min}$, respectively, with ASLAl\% of 30.95\%. The estimated rCBF of the right and left frontal lobes was 73.56 and $59.78 \mathrm{ml} / 100 \mathrm{~g} / \mathrm{min}$, respectively, with ASLAl\% of 20.67\%, while the estimated rCBF of the right and left thalami was 70.04 and $65.69 \mathrm{ml} / 100 \mathrm{~g} / \mathrm{min}$, respectively, with ASLAI\% of 6.41\%. The MV 1H-MRS picture maps illustrating the studied ROls in (b) (I-VI). The MRS spectra of the right and left temporal lobes (c and $\mathbf{d}$, respectively), demonstrated increased MI/NAA, GIx/NAA and GIx/Cr, as well as decreased $\mathrm{NAA} /(\mathrm{Cho}+\mathrm{Cr}$ ) ratios in the zone of epileptogenic activity in the right temporal lobe (c) in comparison to the contra-lateral left temporal lobe (d) with these ratios were: [NAA/(Cho $+\mathrm{Cr}$ ) $=0.59$ and 0.85 with \%AF of $36.11 \%, \mathrm{MI} / \mathrm{NAA}=0.72$ and 0.35 with \%AF of $34.58 \%$, GIX/ $\mathrm{NAA}=1.66$ and 1.34 with \%AF of $21.33 \%$ and $\mathrm{Gl} / \mathrm{Cr}=1.62$ and 1.30 with \%AF of 21.92\%] for the right (c) and left (d) temporal lobes, respectively. On the other hand, the MRS spectra of the contra-lateral left frontal lobe $(\mathbf{f})$ and the contra-lateral left thalamus (h) showed decreased MI/NAA and NAA/(Cho $+\mathrm{Cr}$ ), as well as increased Glx/NAA and $\mathrm{Gl} / \mathrm{Cr}$ ratios when compared to the ipsilateral frontal lobe (e) and thalamus (g). These ratios were $[\mathrm{NAA} /(\mathrm{Cho}+\mathrm{Cr})=0.72$ and 0.67 with \%AF of $7.19 \%, \mathrm{MI} / \mathrm{NAA}=0.38$ and 0.27 with \%AF of $33.85 \%, \mathrm{Gl} / \mathrm{NAA}=$ 1.33 and 1.65 with \%AF of $21.47 \%$ and $\mathrm{GlX} / \mathrm{Cr}=1.28$ and 1.59 , with \%AF of $21.60 \%$ ] for the right and left frontal lobes, respectively, while these ratios were $[\mathrm{NAA} /(\mathrm{Cho}+\mathrm{Cr})=0.71$ and 0.58 with \%AF of $20.16 \%, \mathrm{MI} / \mathrm{NAA}=0.42$ and 0.20 with \%AF of $70.97 \%$, Glx/ NAA $=1.30$ and 1.55 with $\% \mathrm{AF}$ of $8.77 \%$ and $\mathrm{GIX} / \mathrm{Cr}=1.27$ and 1.52 , with \%AF of $8.96 \%$ ] for the right and left thalami, respectively

Moreover, Davis et al. [34] observed elevated NAA/Cr in the epileptogenic focus when compared to the corresponding contralateral region. However, Simister et al. [35] concluded that temporal lobe epilepsy was associated with reduction in $\mathrm{NAA} / \mathrm{Cr}$ ratio in both ipsilateral and contra-lateral temporal lobes. Also, Ercan et al. [36] observed a non-significant reduction in both NAA/Cr and NAA $/(\mathrm{Cho}+\mathrm{Cr})$ ratios in patients with left temporal lobe epilepsy compared to normal controls. These dissimilarities may be referred to differences in the study design, selection criteria, the time of estimation of these metabolites after seizure onset and the disease chronicity. Many explanations were provided to elucidate the mechanism of the NAA reduction in the proposed epileptogenic zone, including neuronal loss, seizure duration, frequency and severity [23] in addition to reduction in synaptic density due to metabolic impairment [36].

The Glx complex is highly involved in the excitatory neuronal activity, and its increased level can be considered as a marker of epileptogenic processes particularly in non-lesional epilepsy [37]. Many previous studies that support the hypothesis of increased glutamate level in the epileptogenic foci assume that elevated glutamate level within the glial-neuronal unit is a key sign of both mitochondrial and metabolic injury induced by the hyper-excitable state that characterizes seizures [37]. Also, the elevated extracellular Glx concentration in those patients can be explained by reduction in glutamate reuptake [32]. Additionally, Savic et al. [38] stated that the alterations in Glx/NAA and Glx/Cr peak ratios could play a crucial role in evaluating patients of temporal lobe epilepsy with negative MRI.

In agreement with the results obtained by previous studies [34, 35, 38], the present study revealed a significant increase in the mean peak ratios of Glx/NAA and Glx $/ \mathrm{Cr}(P<0.001$ and $P<0.018$, respectively $)$ in the suggested zone of focal epileptogenic activity when compared to the corresponding region in the contralateral hemisphere. In contrast, Hammena et al. [39] reported an increase in the Glx concentration contra-lateral to the epileptogenic focus in patients with MRI negative results and postulated a possible neuronal damage contralateral to epileptogenic focus. 

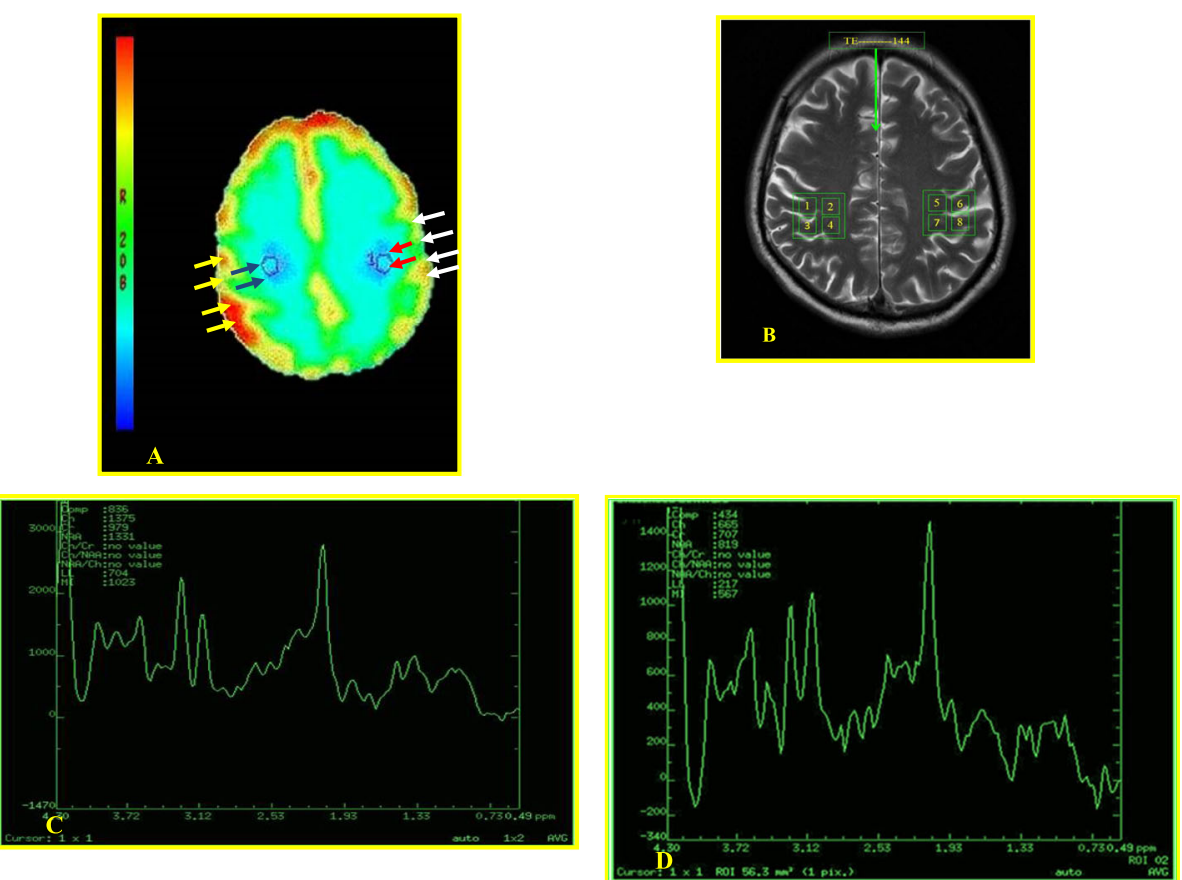

Fig. 6 a-d A 35-year-old female patient with non-lesional left parietal lobe FIAE. The visual-based analysis of the axial PASL-MRI colour-coded cerebral perfusion map (a) demonstrated 2 mirrored focal hypoperfusion areas in the right and left parietal lobes, which represented a mirror focus of cerebral area of seizure spread (blue arrows) and the focal epileptogenic zone (red arrows), respectively, and exhibited cool blue colour, according to the colour scale, reflecting the associated decrease in the rCBF. Additionally, based on the colour-coded spectrum, a cortical and subcortical relative hypoperfusion with associated decrease in the rCBF of the left parietal region is seen displaying green and dark yellow colours (white arrows), when compared to the normal perfusion pattern of the corresponding contra-lateral cortical and subcortical right parietal lobe that tinted with red and yellow colours (yellow arrows). The estimated rCBF for the right and left parietal lobes was 78.68 and $57.91 \mathrm{ml} / 100 \mathrm{~g} /$ min, respectively, with ASLAI\% of 30.41\%. The MV 1 H-MRS picture maps illustrating the studied ROls of both parietal lobes, were obtained at a long TE of 144 ms (b) and short TE of 35 ms. The MV 1H-MRS spectra of the left parietal lobe (d) demonstrated the zone of focal epileptogenic activity with increased MI/NAA, Glx/NAA and Glx/Cr, as well as, decreased NAA/(Cho + $\mathrm{Cr}$ ) ratios, while the MV $1 \mathrm{H}-\mathrm{MRS}$ spectra of the right parietal lobe (c) demonstrated a mirror focus of cerebral area of seizure spread with decreased MI/NA and NAA/(Cho $+\mathrm{Cr}$ ), as well as increased GIX/NAA and GIX/Cr ratios. For the right and left parietal lobes (c and $\mathbf{d}$, respectively), these ratios were [NAA/(Cho $+\mathrm{Cr}$ ) $=0.66$ and 0.46 with $\% \mathrm{AF}$ of $35.71 \%, \mathrm{MI} / \mathrm{NAA}=0.69$ and 0.83 with \%AF of $18.42 \%, \mathrm{GI} / \mathrm{NAA}=1.31$ and 1.49 with \%AF of $12.86 \%$ and $\mathrm{Gl} / \mathrm{Cr}=1.29$ and 1.45 with \%AF of $11.68 \%]$

The peak value of MI concentration could be an essential marker of the biologic effects of overt and/or occult seizure activity, which can provide an early key sign of secondary brain damage [40]. The study in hand demonstrated a significant increase in the mean MI/NAA peak ratio in the suggested zone of focal epileptogenic activity when compared to the homologous region on the contralateral hemisphere $(P=0.044)$. On the contrary, Doelken et al. [32] noted a non-significant change in cerebral MI concentration in both temporal lobes of MRI-negative patients with temporal lobe epilepsy. However, Wellard et al. [40] observed an elevation of MI

Table 4 Quantitative analysis of the PASL-MRI results of both cerebral hemispheres of the studied patients $(n=26)$

\begin{tabular}{|c|c|c|c|c|c|}
\hline \multirow[t]{2}{*}{ Selected ROIs } & \multicolumn{2}{|l|}{$\mathrm{rCBF}(\mathrm{ml} / 100 \mathrm{~g} / \mathrm{min})}$. & \multicolumn{2}{|l|}{ ANOVA } & \multirow[t]{2}{*}{ ASLAI\% } \\
\hline & Ipsilateral hemisphere & $\begin{array}{l}\text { Contralateral } \\
\text { hemisphere }\end{array}$ & $\bar{F}$ & $P$ value & \\
\hline $\begin{array}{l}\text { Epileptogenic zone and its mirrored non- } \\
\text { epileptic contralateral regions }\end{array}$ & $66.22-76.45(73.67 \pm 4.55)$ & $78.68-88.50(82.62 \pm 5.54)$ & 135.402 & $<0.001^{*}$ & $14.34-29.76(18.65 \pm 10.12)$ \\
\hline The thalamus & $68.15-77.08(72.62 \pm 4.46)$ & $71.15-80.09(76.62 \pm 5.47)$ & 1.462 & $0.023^{*}$ & $7.71-10.64(9.23 \pm 1.17)$ \\
\hline The basal ganglia & $72.01-79.09(75.05 \pm 3.04)$ & $73.01-79.10(76.05 \pm 3.05)$ & 1.104 & 0.279 & $3.82-8.21(5.98 \pm 1.22)$ \\
\hline The cerebellum & $72.05-78.27(74.16 \pm 3.11)$ & 72.39-78.63 (74.50 \pm 3.11$)$ & 0.572 & 0.456 & $0.51-4.05(2.2 \pm 1.4)$ \\
\hline Apparently normal brain tissue & $70.21-79.33(75.21 \pm 4.01)$ & $71.22-79.34(75.22 \pm 4.01)$ & 0.650 & 0.568 & $0.01-1.195(1.1 \pm 0.09)$ \\
\hline
\end{tabular}

$R O / \mathrm{s}$ regions of interest, $r C B F$ regional cerebral blood flow, $\mathrm{m} /$ milliliter, $g$ grams, min minute, $A S L A / \%$ arterial spin labelled asymmetry index (percent), $F$ Fischer's exact test value, * significant $(P<0.05)$. Data are expressed in range (mean \pm standard deviation) 
Table 5 The mean metabolite concentration ratios in brains of the studied patients $(n=26)$

\begin{tabular}{|c|c|c|c|c|c|}
\hline Metabolite ratio in different brain regions & & $\begin{array}{l}\text { Ipsilateral side of the } \\
\text { epileptogenic zone }\end{array}$ & $\begin{array}{l}\text { Contralateral } \\
\text { side }\end{array}$ & $t$ & $\begin{array}{l}P \\
\text { value }\end{array}$ \\
\hline \multirow[t]{6}{*}{$\begin{array}{l}\text { Suggested zone of focal epileptogenic activity and its mirrored non- } \\
\text { epileptic contralateral region }\end{array}$} & NAA/Cho & $0.94 \pm 0.08$ & $1.21 \pm 0.18$ & 5.341 & $\begin{array}{l}< \\
0.02^{*}\end{array}$ \\
\hline & $\mathrm{NAA} / \mathrm{Cr}$ & $0.86 \pm 0.11$ & $1.28 \pm 0.14$ & 1.181 & $0.01^{*}$ \\
\hline & $\begin{array}{l}\text { NAA/ } \\
(\mathrm{Cho}+\mathrm{Cr})\end{array}$ & $0.54 \pm 0.62$ & $0.93 \pm 0.07$ & 21.540 & $\begin{array}{l}< \\
0.001^{*}\end{array}$ \\
\hline & MI/NAA & $1.03 \pm 0.21$ & $0.72 \pm 0.10$ & 2.068 & $0.044^{*}$ \\
\hline & GIx/NAA & $1.56 \pm 1.25$ & $1.23 \pm 1.12$ & 18.451 & $\begin{array}{l}< \\
0.001^{*}\end{array}$ \\
\hline & $\mathrm{Glx} / \mathrm{Cr}$ & $1.44 \pm 0.24$ & $1.21 \pm 0.44$ & 3.441 & $\begin{array}{l}< \\
0.018^{*}\end{array}$ \\
\hline \multirow[t]{6}{*}{ Cerebral areas of seizure spread } & NAA/Cho & $1.23 \pm 0.18$ & $1.25 \pm 0.18$ & 2.344 & 0.163 \\
\hline & $\mathrm{NAA} / \mathrm{Cr}$ & $1.27 \pm 0.14$ & $1.29 \pm 0.14$ & 3.235 & 0.132 \\
\hline & $\begin{array}{l}\text { NAA/ } \\
(\mathrm{ChO}+\mathrm{Cr})\end{array}$ & $0.84 \pm 0.14$ & $0.87 \pm 0.15$ & 5.416 & 0.072 \\
\hline & MI/NAA & $0.50 \pm 0.01$ & $0.69 \pm 0.19$ & 2.178 & $\begin{array}{l}< \\
0.01^{*}\end{array}$ \\
\hline & Glx/NAA & $1.28 \pm 15$ & $1.26 \pm 14$ & 1.246 & 0.120 \\
\hline & $\mathrm{Gl} / \mathrm{Cr}$ & $1.23 \pm 0.26$ & $1.22 \pm 0.26$ & 1.521 & 0.641 \\
\hline \multirow[t]{6}{*}{ Thalamus } & NAA/Cho & $1.19 \pm 0.05$ & $1.22 \pm 0.06$ & 35.254 & $<0.11$ \\
\hline & $\mathrm{NAA} / \mathrm{Cr}$ & $1.23 \pm 0.11$ & $1.26 \pm 0.12$ & 24.351 & $<0.43$ \\
\hline & $\begin{array}{l}\text { NAA/ } \\
(\mathrm{Cho}+\mathrm{Cr})\end{array}$ & $0.60 \pm 0.12$ & $0.92 \pm 0.13$ & -4.73 & $\begin{array}{l}< \\
0.001^{*}\end{array}$ \\
\hline & MI/NAA & $0.67 \pm 0.13$ & $0.72 \pm 0.03$ & 26.081 & $0.03^{*}$ \\
\hline & GIx/NAA & $1.49 \pm 20$ & $1.27 \pm 19$ & 1.246 & $\begin{array}{l}< \\
0.02^{*}\end{array}$ \\
\hline & $\mathrm{Gl} / \mathrm{Cr}$ & $1.40 \pm 0.32$ & $1.37 \pm 0.31$ & 1.521 & 0.064 \\
\hline \multirow[t]{6}{*}{ Basal ganglia } & NAA/Cho & $1.24 \pm 0.07$ & $1.26 \pm 0.08$ & 1.870 & 0.910 \\
\hline & $\mathrm{NAA} / \mathrm{Cr}$ & $1.27 \pm 0.10$ & $1.25 \pm 0.11$ & 0.371 & 0.865 \\
\hline & $\begin{array}{l}\text { NAA/ } \\
(\mathrm{Cho}+\mathrm{Cr})\end{array}$ & $0.84 \pm 0.12$ & $0.87 \pm 0.13$ & 0.521 & 0.160 \\
\hline & MI/NAA & $0.81 \pm 0.01$ & $0.79 \pm 0.02$ & 0.462 & 0.754 \\
\hline & Glx/NAA & $1.25 \pm 24$ & $1.23 \pm 23$ & 0.162 & 0.110 \\
\hline & $\mathrm{Glx} / \mathrm{Cr}$ & $1.25 \pm 0.39$ & $1.23 \pm 0.37$ & 1.253 & 0.064 \\
\hline \multirow[t]{6}{*}{ Cerebellar hemispheres } & NAA/Cho & $1.27 \pm 0.11$ & $1.23 \pm 0.10$ & 1.355 & 0.183 \\
\hline & $\mathrm{NAA} / \mathrm{Cr}$ & $1.28 \pm 0.17$ & $1.25 \pm 0.16$ & 1.095 & 0.279 \\
\hline & $\begin{array}{l}\text { NAA/ } \\
(\mathrm{ChO}+\mathrm{Cr})\end{array}$ & $0.86 \pm 0.16$ & $0.82 \pm 0.15$ & 0.731 & 0.468 \\
\hline & MI/NAA & $0.76 \pm 0.12$ & $0.77 \pm 0.11$ & 1.651 & 0.124 \\
\hline & Glx/NAA & $1.27 \pm 20$ & $1.29 \pm 20$ & 0.162 & 0.210 \\
\hline & $\mathrm{Gl} / \mathrm{Cr}$ & $1.23 \pm 0.40$ & $1.26 \pm 0.39$ & 1.253 & 0.064 \\
\hline
\end{tabular}

MV 1 H-MRS multi-voxel proton magnetic resonance spectroscopy, ppm parts per million, NAA N-acetylaspartate, $\mathrm{Cr}$ creatine, Cho choline, Glx glutamate-glutamine, $M I$ Myo-inositol, $t t$ test, ${ }^{*}$ significant if $P$ value $<0.05$

concentration ipsilateral to the epileptogenic temporal lobe in patients with hippocampal sclerosis compared to the corresponding contra-lateral temporal lobe and normal controls. They attributed this change to the associated astrocytosis [40].
Temporal lobes have rich functional interconnectivity with other brain regions, in which the posterior lateral temporal region serves as the spot of a "functional hub" which is a key for the propagation of ictal activity to other brain regions, causing the clinical phenomenon of 
Table 6 The \%AF of the mean metabolites concentration ratio obtained by multivoxel $1 \mathrm{H}-\mathrm{MRS}$ in the studied patients $(n=26)$

\begin{tabular}{|c|c|c|c|c|c|c|c|}
\hline \multirow{2}{*}{\multicolumn{2}{|c|}{$\begin{array}{l}\text { Laterality of the epileptogenic activity } \\
\text { as obtained by } 1 \mathrm{H}-\mathrm{MRS} \text { data }\end{array}$}} & \multicolumn{6}{|c|}{ The \%AF of the mean metabolites ratios } \\
\hline & & \multirow{2}{*}{$\begin{array}{l}\text { NAA/Cho } \\
4.2\end{array}$} & \multirow{2}{*}{$\begin{array}{l}\text { NAA/Cr } \\
3.5\end{array}$} & \multirow{2}{*}{$\begin{array}{l}\mathrm{NAA} /(\mathrm{Cho}+\mathrm{Cr}) \\
3.3\end{array}$} & \multirow{2}{*}{$\begin{array}{l}\text { MI/NAA } \\
4\end{array}$} & \multirow{2}{*}{$\begin{array}{l}\text { GIx/NAA } \\
3\end{array}$} & \multirow{2}{*}{$\begin{array}{l}\mathrm{Glx} / \mathrm{Cr} \\
4\end{array}$} \\
\hline Trivial \%AF with no later & zation (1/26; 3.85\%) & & & & & & \\
\hline \multirow[t]{2}{*}{$\begin{array}{l}\text { \%AF with lateralization } \\
(25 / 26 ; 96.15 \%\end{array}$} & $\begin{array}{l}\text { Right lateralization } \\
(12 ; 46.15 \%)\end{array}$ & $\begin{array}{l}-1.5-37.5 \\
(25.2 \pm 2.2)\end{array}$ & $\begin{array}{l}-1.5-30 \\
(24.6 \pm 5)\end{array}$ & $\begin{array}{l}-1.5-29.8 \\
(27.4 \pm 1.7)\end{array}$ & $\begin{array}{l}-1.49-24 \\
(20.5 \pm 2.3)\end{array}$ & $\begin{array}{l}-1.2-30.6 \\
(20.0 \pm 1.8)\end{array}$ & $\begin{array}{l}-1.1-38.9 \\
(25.1 \pm 13)\end{array}$ \\
\hline & $\begin{array}{l}\text { Left lateralization } \\
(13 ; 50 \%)\end{array}$ & $\begin{array}{l}15-37 \\
(26.0 \pm 1.1)\end{array}$ & $\begin{array}{l}12-31.4 \\
(25.1 \pm 4.4)\end{array}$ & $\begin{array}{l}12-30.2 \\
(29.1 \pm 1.5)\end{array}$ & $\begin{array}{l}10.5-35.7 \\
(22.0 \pm 12)\end{array}$ & $\begin{array}{l}13.9-30.5 \\
(21.5 \pm 11)\end{array}$ & $\begin{array}{l}12-30.01 \\
(26.2 \pm 12)\end{array}$ \\
\hline \multirow[t]{2}{*}{ ANOVA } & $\mathrm{F}$ & 66.44 & 149.613 & 27.87 & 39.41 & 1.462 & 1.104 \\
\hline & $P$ value & $<0.001^{*}$ & $<0.002^{*}$ & $<0.001^{*}$ & $<0.01^{*}$ & $0.02^{*}$ & $0.03^{*}$ \\
\hline
\end{tabular}

MV 1 H-MRS multi-voxel proton magnetic resonance spectroscopy, ppm parts per million, NAA N-acetylaspartate, $\mathrm{Cr}$ creatine, Cho choline, Glx glutamate-glutamine, MI Myo-inositol, \%AF percent asymmetry factor; statistical data were expressed as number ( $n$ ); percent (\%), mean \pm standard deviation (SD) and $F$ Fisher exact test, *: significant if $P$ value $` 0.05$

secondary generalization [41]. Obviously, patients with temporal lobe epilepsy show an additional hypometabolism of the frontal, parietal and occipital lobes, which represents the inhibitory phenomena initiated by the epileptogenic focus [42, 43].

In the current study, despite the significant increase of the MI/NAA ratio in the epileptogenic zones in patients of false localization (Figs. 3 and 4) and false lateralization (Figs. 5 and 6) on PASL-MRI, there was a significant reduction of this metabolite ratio in the regions of seizure spread $(P<0.01)$, which might be attributed to the osmolyte changes caused by seizures [40]. These areas with diminished MI/NAA ratios were considered as cerebral areas of propagation of epileptogenic activity. Wellard et al. [40] advocated the use of this finding in discrimination between the seizure focus with increased MI concentration and the areas of seizure spread with reduced MI concentration. The hypometabolism observed in other brain lobes ipsilateral and/or contralateral to the epileptogenic temporal lobe can be attributed to the seizure spread and propagation to these brain regions $[23,31,43]$.
In humans, the thalamus displays reciprocal widespread connections with subcortical structures and other cortical regions [44] and is thought to be responsible for the initiation and expression of partial and generalized seizures. Therefore, the role of the thalamus in localization-related epilepsy has currently been receiving attention [45]. The present study reported a case with right temporal lobe FIAE that appeared normal by PASL-MRI and considered a false negative result, while the 1H-MRS showed increased Glx/NAA, decreased $\mathrm{NAA} /(\mathrm{Cho}+\mathrm{Cr})$ and decreased MI/NAA ratios of the right temporal lobe and ipsilateral thalamus (Fig. 1). This goes in harmony with the results obtained by Jain et al. [46], who stated that ipsilateral thalamic hypometabolism played an important role in localization of the epileptogenic focus in patients with temporal lobe epilepsy.

The present study demonstrated significant thalamic changes detected ipsilateral to the epileptogenic zone in two patients [one with frontal lobe FIAE (Fig. 2), and one with temporal lobe FIAE (Fig. 3)], and in the contralateral thalamus in one patient with right temporal lobe FIAE (Fig. 5). These thalamic changes included

Table 7 Cut-off values with sensitivity, specificity, predictive values and accuracy of PASL-MRI and 1H-MRS in identification of epileptogenic zone in patients with FIAE $(n=26)$

\begin{tabular}{|c|c|c|c|c|c|c|c|c|c|}
\hline \multicolumn{3}{|c|}{ Quantitative imaging parameters } & \multirow{2}{*}{$\begin{array}{l}\text { Cut-off } \\
\leq 64.87\end{array}$} & \multirow{2}{*}{$\frac{\text { AUC }}{0.957}$} & \multirow{2}{*}{$\begin{array}{l}\text { Sensitivity \% } \\
98.31\end{array}$} & \multirow{2}{*}{$\begin{array}{l}\text { Specificity \% } \\
92.90\end{array}$} & \multirow{2}{*}{$\begin{array}{l}\text { PPV \% } \\
95.97\end{array}$} & \multirow{2}{*}{$\begin{array}{l}\text { NPV \% } \\
88.89\end{array}$} & \multirow{2}{*}{$\frac{\text { Accuracy \% }}{94.75}$} \\
\hline PASL-MRI parameters & $\mathrm{rCBF}(\mathrm{ml} / 100 \mathrm{~g} / \mathrm{min})$ & & & & & & & & \\
\hline & ASLAI \% & & $\geq 5.96 \%$ & 0.968 & 96.01 & 91.70 & 89.68 & 95.82 & 95.78 \\
\hline \multirow[t]{7}{*}{ MV 1H-MRS parameters } & \multirow{6}{*}{$\begin{array}{l}\text { Metabolite concentration } \\
\text { ratios (in ppm) }\end{array}$} & NAA/Cho & $\leq 0.78$ & 0.949 & 93.0 & 91.7 & 90.8 & 92.7 & 93.94 \\
\hline & & $\mathrm{NAA} / \mathrm{Cr}$ & $\leq 0.89$ & 0.889 & 89.3 & 88.2 & 92.6 & 83.3 & 88.9 \\
\hline & & $\mathrm{NAA} /(\mathrm{Cho}+\mathrm{Cr})$ & $\leq 0.59$ & 0.977 & 100 & 96.9 & 96.7 & 100 & 97.74 \\
\hline & & MI/NAA & $\geq 0.98$ & 0.989 & 100 & 96.34 & 95.38 & 100 & 97.86 \\
\hline & & GlX/NAA & $\geq 1.55$ & 0.972 & 100 & 96.35 & 95.68 & 100 & 97.24 \\
\hline & & $\mathrm{Glx} / \mathrm{Cr}$ & $\geq 1.39$ & 0.955 & 92.06 & $90.24 \%$ & 93.88 & 93.67 & 94.53 \\
\hline & $\% A F$ & & $\geq 9.98 \%$ & 0.983 & 100 & 97.65 & 98.31 & 100 & 98.14 \\
\hline \multicolumn{5}{|c|}{ Combined use of ASL-MRI and MV 1H-MRS } & 100 & 98.45 & 97.81 & 99.6 & 98.86 \\
\hline
\end{tabular}

PPV positive predictive value, NPV negative predictive value, $M V 1 H-M R S$ multi-voxel proton magnetic resonance spectroscopy, ppm parts per million, $N A A$ acetylaspartate, $\mathrm{Cr}$ creatine, Cho choline, Glx glutamate-glutamine, MI Myo-inositol, $A S L A l \%$ arterial spin labelled asymmetry index (percent), \%AF percent asymmetry factor, $r C B F$ regional cerebral blood flow, $\mathrm{ml}$ milliliter, $g$ grams, min minute 


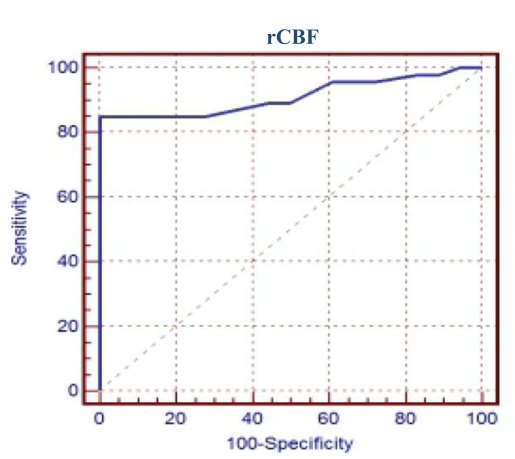

A

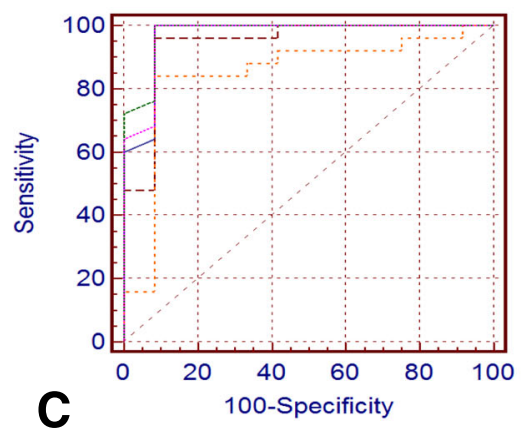

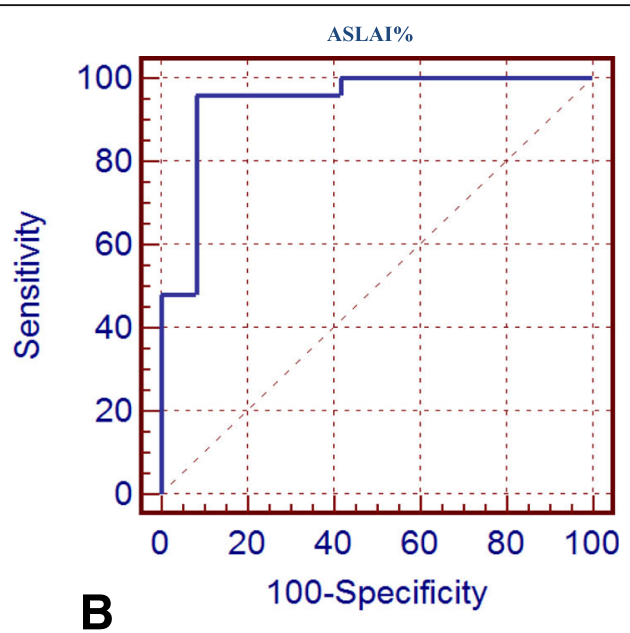

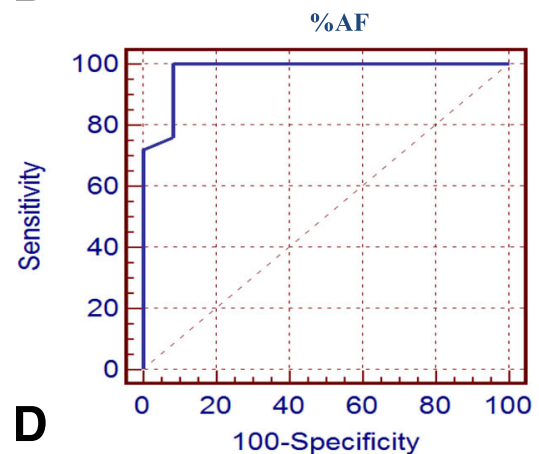

Fig. 7 a-d The ROC curves analysis illustrates the performance of quantitative parameters of PASL-MRI and 1H-MRS techniques in identification of the zone of epileptogenic activity in the studied patients. The rCBF at a cut-off value $\leq 64.87 \mathrm{ml} / 100 \mathrm{~g} / \mathrm{min}$ with 0.957 AUC showed $98.31 \%$ sensitivity, $92.90 \%$ specificity and $94.75 \%$ accuracy and by using the ASLAI\% at a cut-off value $\geq 5.96$ with 0.968 AUC, yielded $96.01 \%$ sensitivity, 91.70\% specificity and $95.78 \%$ accuracy (a and $\mathbf{b}$, respectively). Moreover, c revealed that NAA/Cho ratio at a cut-off value $\leq 0.78$ with 0.949 AUC, gave $93.0 \%$ sensitivity, $91.7 \%$ specificity and $93.94 \%$ accuracy, while NAA/Cr ratio at a cut-off value $\leq 0.89$ with 0.889 AUC showed $89.3 \%$ sensitivity, $88.2 \%$ specificity and $88.9 \%$ accuracy. On the other hand, NAA/(Cho + Cr) ratio at a cut-off value $\leq 0.59$ with 0.977 AUC, yielded $100 \%$ sensitivity, $96.9 \%$ specificity and $97.74 \%$. Also, MI/NAA ratio at a cut-off value $\geq 0.98$ with 0.989 AUC, yielded $100 \%$ sensitivity $96.34 \%$ specificity and $97.86 \%$ accuracy, while GIx/NAA ratio at a cut-off value $\geq 1.55$ with 0.972 AUC, yielded $100 \%$ sensitivity, $96.35 \%$ specificity and $97.24 \%$ accuracy, while GIX/Cr ratio at a cut-off value $\geq 1.39$ with 0.955 AUC, showed $92.06 \%$ sensitivity, $90.24 \%$ specificity and $94.53 \%$ accuracy. Furthermore, utilization of \%AF at a cut-off value $\geq 9.98$ with 0.983 AUC, gave $100 \%$ sensitivity, $97.65 \%$ specificity and $98.14 \%$ accuracy (d)

significant reduction in the $\mathrm{rCBF}(P=0.023)$ by PASLMRI, in addition to a significant reduction in the NAA/ $(\mathrm{Cho}+\mathrm{Cr})$ ratio $(P<0.001)$ and a significant increase in Glx/NAA ratio $(P=0.02)$ by $1 \mathrm{H}-\mathrm{MRS}$. This is supported by the results of previous studies [44-48], which recommended the utilization of interictal thalamic hypoperfusion and/or metabolic alterations as a complementary sign for proper localization and lateralization of epileptogenic foci in patients with temporal and frontal lobe epilepsy.

A mirror focus is a special pattern of secondary epileptogenesis in which activity is provoked through dense inter-hemispheric callosal or commissural connection networks and considered as one of the signs of epilepsy progression $[49,50]$. In a similar way, the current study showed a patient with left parietal non-lesional FIAE, with false lateralization of the epileptogenic zone based on the PASL-MRI results. The 1H-MRS of this patient detected properly the lateralization of the epileptogenic zone in the left parietal region, wherein there was reduced NAA/(Cho $+\mathrm{Cr})$ and increased MI/NAA ratios in the epileptogenic zone (left parietal), while the MI/NAA ratio was decreased in the corresponding area in the right parietal region that represented a mirror focus of seizure spread (Fig. 6).

To the best of our knowledge, limited studies discussed the optimal cut-off value of PASLAI\% for proper identification of the epileptogenic zone in patients with non-lesional FIAE. Additionally, the vast majority of prior spectroscopic studies addressed the metabolic alterations of the hippocampi and/or temporal lobe, while diminutive attention was paid to other brain regions with a wide argument $[29,30,46]$.

The statistical data analysis of the MV 1H-MRS results yielded a cut-off value $\geq 9.98 \%$ for the increased mean \%AF with AUC 0.981 (100\% sensitivity, 97.65\% specificity and $98.14 \%$ accuracy), and a cut-off value $\leq 0.59$ for 
detection of significant decrease in the NAA/ $(\mathrm{Cho}+\mathrm{Cr})$ ratio with AUC of 0.977 (100\% sensitivity, $96.9 \%$ specificity and $97.74 \%$ accuracy), between the proposed epileptogenic zone and homologues contralateral region. In contrast, Eryurt et al. [29] suggested a cut-off value 8.7\% for increased \%AF between the epileptogenic temporal lobe and contralateral non-epileptic lobe with $86 \%$ sensitivity and $79 \%$ specificity. On the other hand, Elnekidy et al. [33] used a cut-off value $14 \%$ and $9 \%$ to the epileptogenic zones of the anterior and posterior portions of temporal lobe, respectively, while Sharma [51] used a cut-off value $12 \%$ to the total temporal lobe. Moreover, Elnekidy et al. [33] used a cut-off value 0.32 and 0.65 for detection of significant reduction in the NAA/(Cho + $\mathrm{Cr}$ ) concentration ratio in the epileptogenic zones of the anterior and posterior portions of temporal lobe, respectively, while Burtscher and Holtas [52] utilized a cut-off value $<0.71 \%$ for identification of a significant reduction in the $\mathrm{NAA} /(\mathrm{Cho}+\mathrm{Cr})$ ratio ipsilateral to the epileptogenic zone.

Moreover, in the zone of assumed epileptogenic focus, we recorded a mean of $1.03 \pm 0.21$ for significantly increased MI/NAA concentration ratio with an optimal cut-off value $\geq 0.98$ and AUC 0.989 (100\% sensitivity, $96.34 \%$ specificity and $97.86 \%$ accuracy), and a mean of $1.56 \pm 1.25$ for significantly increased Glx/NAA ratio with an optimal cut-off value $\geq 1.55$ and AUC 0.972 (100\% sensitivity, $96.35 \%$ specificity and $97.24 \%$ accuracy). On contrast, Aydin et al. [33] recorded a mean of $1.15 \pm 1.19$ and $1.16 \pm 1.07$ in the right and left hippocampi, respectively, with an AUC $0.450 \pm 0.091$, for significantly increased peak of Glx in the epileptogenic focus in patients with temporal lobe epilepsy, while they reported a mean of $0.76 \pm 0.61$ and $0.60 \pm 0.42$ in the right and left hippocampi, respectively, for significantly increased peak of MI with an AUC 0.434 \pm 0.060 . However, they could not display the optimal cut-off values for the significantly increased peaks of MI and Glx in the epileptogenic focus.

Furthermore, the current work demonstrated that in the interictal state, the combined use of PASL-MRI and MV 1H-MRS enabled accurate localization and lateralization of the epileptogenic zone in patients with FIAE with the highest sensitivity, specificity and accuracy $(100 \%, 98.45 \%$ and $98.86 \%$, respectively).

\section{Limitations}

Although we feel that our prospective study on patients with non-lesional FIAE, in their interictal state, offered an essential insight about the diagnostic performance of PASL-MRI and MV 1H-MRS, this study faced some limitations. First limitation was the small number of the studied patients. Second, our study did not include patients with bilateral epileptogenic activities. Third, we did not include a healthy control group. However, we considered the non-epileptogenic hemisphere as an individual auto-control. So, further extended studies on a larger number of patients with different age groups are recommended with the inclusion of patients with bilateral epileptogenic activity and other types of epilepsy.

\section{Conclusion}

In the interictal states of patients with non-lesional FIAE, the PASL-MRI (including significantly increased ASLAI\% and reduced $\mathrm{rCBF}$ ) and the MV $1 \mathrm{H}$-MRS [including increased MI/NAA and Glx/NAA as well as reduced NAA/(Cho $+\mathrm{Cr})$ ratios] can be considered as valuable non-invasive accurate techniques for proper identification of the epileptogenic zone. Moreover, ipsilateral thalamic metabolic alterations including elevated Glx/NAA and MI/NAA peak ratios can facilitate proper lateralization and localization of the epileptogenic zone, while the reduction in the MI/NAA ratio can be used as an indicator for identification of the area of seizure spread.

The combined use of PASL-MRI (with coloured perfusion maps of rCBF) and MV 1H-MRS (which is considered as a metabolic biopsy) permits much higher diagnostic accuracy than utilization of each sequence alone (100\% sensitivity, $98.45 \%$ specificity, and $98.86 \%$ accuracy). This combination provides in-vivo digital proficient biomarker that enhances the accurate identification of the epileptogenic focus and the cerebral areas of seizure spread in this specific category of epileptic patients with conventional MRI-negative results.

We immensely recommend the employment of these MRI techniques as a part of the routine imaging workup protocol in patients with non-lesional epilepsy, particularly those prone to develop intravenous contrast/radiotracer harmful effects.

\section{Abbreviations \\ Cho: Choline; Cr: Creatine; ERC: Ethical Research Committee; Glx: Glutamine + glutamate; MV 1H-MRS: Multi-voxel proton magnetic resonance \\ spectroscopy; MI: Myo-inositol; NAA: N-acetylaspartate; PASL-MRI: Pulsed arterial spin-labeling magnetic resonance imaging; rCBF: Regional cerebral blood flow}

\section{Acknowledgements \\ None.}

\section{Authors' contributions}

REM (the corresponding author) suggested the research idea, collected data in all stages of manuscript, ensured the original figures and data in the work, correlated the clinical data of the studied patients and matched it with the imaging findings, with significant contribution to design the methodology, as well as, editing, preparation and revision of the manuscript. AAA performed sample collection with clinical neurological assessment, suggested the study design, minimized the obstacles to the team of work and had a major role in the statistical data analysis, editing and revision of the manuscript. RMD shared in sample collection, correlated the clinical data of patients and matched them with the radiological findings. All authors read and approved the final manuscript. 


\section{Funding}

The authors declare that the current study had no funding from any resource.

\section{Availability of data and materials}

The authors confirm that all data supporting the findings of the current study are available within the article. Also, all the data sets used and/or analysed during the current study are available from the corresponding author on a reasonable request.

\section{Ethics approval and consent to participate}

The current study was approved by the Ethical Research Committee (ERC) of Tanta University, Faculty of Medicine, and an official permission to carry out the present study (Approval Code: 33960/7/20) was obtained from the responsible authorities. All procedures performed in the current study, involving human participants, were in accordance with the ethical standards of the institutional research committee and with the 1964 Helsinki declaration and its later amendments. Additionally, all potential hazards were explained to the participants and their families with all participants gave their written informed consent before the start of the study. For unconscious patient or patient with decreased conscious level, written informed consent was obtained by their legal guardian before the start of the study.

\section{Consent for publication}

All subjects included in the current research gave their written informed consent to publish the data contained within the study. If the patients were equal to or less than 16 years old, deceased or unconscious when consent for publication was requested, written informed consent for the publication of this data was given by their parents or legal guardian.

\section{Competing interests}

The authors declare that they have no competing interests.

\section{Author details}

${ }^{1}$ Radiodiagnosis and Medical Imaging Department, Tanta University, Tanta, Egypt. ${ }^{2}$ Neurology Department, Tanta University, Tanta, Egypt.

Received: 16 July 2020 Accepted: 22 September 2020

Published online: 02 October 2020

\section{References}

1. Aun AK, Mostafa AA, Aboul Fotouh AM et al (2016) Role of magnetic resonance spectroscopy (MRS) in nonlesional temporal lobe epilepsy. Egyptian J Radiol Nuclear Med 47:217-231

2. Ngugi AK, Bottomley C, Kleinschmidt I, Sander JW, Newton CR (2010) Estimation of the burden of active and life-time epilepsy: a meta-analytic approach. Epilepsia. 51:883-890

3. National Clinical Guideline Centre (UK) (2012) The epilepsies: the diagnosis and management of the epilepsies in adults and children in primary and secondary care. Royal College of Physicians (UK), London

4. Tobochnik S, Gutierrez C, Crino P, Connolly P (2012) Refractory Nonlesional Neocortical Epilepsy: Current Trends. J Neurol Neurophysiol S2:004

5. Bernhardt BC, Worsley KJ, Kim H et al (2009) Longitudinal and crosssectional analysis of atrophy in pharmaco-resistant temporal lobe epilepsy. Neurology 72:1747-1754

6. Luders HO, Najm I, Nair D, Widdess-Walsh P, Bingman W (2006) The epileptogenic zone: general principles. Epileptic Disord 8(Suppl. 2):S1-S9

7. Pendse N, Wissmeyer M, Altrichter $S$ et al (2010) Inter-ictal arterial spinlabeling MRI perfusion in intractable epilepsy. J Neuroradiol 37:60-63

8. Bien CG, Szinay M, Wagner J et al (2009) Characteristics and surgical outcomes of patients with refractory magnetic resonance imaging-negative epilepsies. Arch Neurol 66:1491-1499

9. Deibler AR, Pollock JM, Kraft RA et al (2008) Arterial spin-labeling in routine clinical practice. Part 1: technique and artifacts. Am J Neuroradiol 29:12281234

10. Duncan JS (2010) Imaging in the surgical treatment of epilepsy. Nat Rev Neurol 6(10):537-550

11. Kim BS, Lee S-T, Yun TJ et al (2016) Capability of arterial spin labeling MR imaging in localizing seizure focus in clinical seizure activity. Eur J Radiol 85: 1295-1303
12. Sierra-Marcos A, Carreño M, Setoain X et al (2016) Accuracy of arterial spin labeling magnetic resonance imaging (MRI) perfusion in detecting the epileptogenic zone in patients with drug-resistant neocortical epilepsy: comparison with electrophysiological data, structural MRI, SISCOM and FDGPET. Eur J Neurol 23(1):160-167

13. Brázdil M, Mikl M, Chlebus P, Pažourková M, Novák Z, Chrastina J et al (2006) Combining advanced neuroimaging techniques in presurgical workup of non-lesional intractable epilepsy. Epileptic Disord 8(3):190-194

14. Fisher RS, Cross JH, D'Souza C et al (2017) Instruction manual for the ILAE 2017 operational classification of seizure types. Epilepsia 58(4):531-542

15. Kantarci K, Smith GE, Ivnik RJ et al (2002) 1H-magnetic resonance spectroscopy, cognitive function and apolipoprotein-E genotype in normal aging, mild cognitive impairment and Alzheimer's disease. J Int Neuropsychol Soc 8(7):934-942

16. Flink R, Pedersen B, Guekht AB et al (2002) Guidelines for the use of EEG methodology in the diagnosis of epilepsy. Acta Neurol Scand 106:1-7

17. Yoo R-E, Yun TJ, Yoon B-W, Lee SK, Lee S-T, Kang KM et al (2017) Identification of cerebral perfusion using arterial spin labeling in patients with seizures in acute settings. PLOS ONE 12(3):e 0173538

18. Bansal V, Kumar S, Sharma S et al (2017) Usefulness of pulsed arterial spin labeling magnetic resonance imaging in new-onset seizure patients and its comparison with dynamic susceptibility contrast magnetic resonance imaging. J Neurosci Rural Pract 8:569-574

19. Capizzano AA, Vermathen P, Laxer KD et al (2002) Multisection proton MR spectroscopy for mesial temporal lobe epilepsy. AJNR Am J Neuroradiol 23(8):1359-1368

20. Zhang J, Liu Q, Mei S et al (2014) Identifying the affected hemisphere with a multimodal approach in MRI-positive or negative, unilateral or bilateral temporal lobe epilepsy. Neuropsychiatr Dis Treat:1071-1081

21. Kassem H, El Shiekh F, Wafaie A et al (2013) Presurgical evaluation of refractory temporal lobe epilepsy: comparison of MR imaging, PET and ictal SPECT in localization of the epileptogenic substrate. Egyptian J Radiol Nuclear Med 44:641-649

22. Stamoulis C, Verma N, Kaulas H et al (2017) The promise of subtraction ictal SPECT co-registered to MRI for improved seizure localization in pediatric epilepsies: Affecting factors and relationship to the surgical outcome. Epilepsy Res 129:59-66

23. Kumar A, Chugani HT (2017) The role of radionuclide imaging in epilepsy, Part 1: Sporadic temporal and extra-temporal lobe epilepsy. J Nucl Med Technol 45:14-21. https://doi.org/10.2967/jnumed.112.114397

24. Deibler AR, Pollock JM, Kraft RA et al (2008) Arterial spin-labeling in routine clinical practice, Part 2: hypoperfusion patterns. Am J Neuroradiol 29:12351241

25. Oner AY, Eryurt B, Ucar M et al (2015) PASL versus DSC perfusion MRI in lateralizing temporal lobe epilepsy. Acta Radiol 56(4):477-481

26. Galazzo B, Storti SF, Del Felice A et al (2015) Patient-specific detection of cerebral blood flow alterations as assessed by arterial spin labeling in drugresistant epileptic patients. PLOS ONE 10(5):e0123975. https://doi.org/10. 1371/journal.pone.0123975

27. Jefferys JG (2010) Advances in basic mechanisms of epilepsy and seizures. Seizure 19:638-646

28. Pizzini F, Farace P, Zanoni T et al (2008) Pulsed-arterial-spin labelling perfusion 3T MRI following single seizure: a first case report study. Epilepsy Res 81:225-227

29. Eryurt B, Oner AY, Ucar M et al (2015) Presurgical evaluation understanding of mesial temporal lobe epilepsy with multiple advanced MR techniques at 3T. J Neuroradiol 42(5):283-290. https://doi.org/10.1016/j.neurad.2015.04.002

30. Guo X, Xu S, Wang G et al (2015) Asymmetry of cerebral blood flow measured with three-dimensional pseudocontinuous arterial spin-labeling MR imaging in temporal lobe epilepsy with and without mesial temporal sclerosis. J Magn Reson Imaging 42:1386-1397

31. Tan Q, Sun H, Wang W et al (2018) Quantitative MR spectroscopy reveals metabolic changes in the dorsolateral prefrontal cortex of patients with temporal lobe epilepsy. Eur Radiol. https://doi.org/10.1007/s00330-018-5443-x

32. Doelken MT, Stefan H, Pauli E et al (2008) $1 \mathrm{H}$ MRS profile in MRI positiveversus MRI negative patients with temporal lobe epilepsy. Seizure 17:490497

33. Aydin H, Oktay NA, Kizilgoz V, Altin E, Tatar IG, Hekimoglu B (2012) Value of proton-MR-spectroscopy in the diagnosis of temporal lobe epilepsy; correlation of metabolite alterations with electroencephalography. Iran J Radiol 9(1):1-11 
34. Davis KA, Nanga RPR, Das S et al (2015) Glutamate imaging (GluCEST) lateralizes epileptic foci in non-lesional temporal lobe epilepsy. Sci Trans Med 7(309):309ra161. https://doi.org/10.1126/scitransImed.aaa7095

35. Simister RJ, McLeana MA, Barker GJ, Duncan JS (2009) Proton MR Spectroscopy of metabolite concentrations in temporal lobe epilepsy and effect of temporal lobe resection. Epilepsy Res 83:168-176

36. Ercan K, Gunbey HP, Bilir E et al (2016) Comparative lateralizing ability of multimodality MRI in temporal lobe epilepsy. Dis Markers J Hindawi Pub Corp 5923243:9. https://doi.org/10.1155/2016/5923243

37. Molinari F, Raas-Rothschild A, Rio M et al (2005) Impaired mitochondrial glutamate transport in autosomal recessive neonatal myoclonic epilepsy. Am J Hum Genet 76:334-339

38. Savic I, Thomas AM, Ke Y et al (2000) In vivo measurements of glutamine+ glutamate (G|X) and N-acetyl aspartate (NAA) levels in human partial epilepsy. Acta Neurol Scand 102:179-188

39. Hammena T, Kerlinga F, Schwarz M et al (2006) Identifying the affected hemisphere by $1 \mathrm{H}$-MR spectroscopy in patients with temporal lobe epilepsy and no pathological findings in high resolution MRI. Eur J Neurol 13:482-490

40. Wellard RM, Briellmann RS, Prichard JW, Syngeniotis A, Jackson GD (2003) Myoinositol abnormalities in temporal lobe epilepsy. Epilepsia 44(6):815-821

41. Yoo JY, Farooque P, Chen W et al (2014) Ictal spread of medial temporal lobe seizures with and without secondary generalization: an intracranial EEG analysis. Epilepsia. 55(2):289-295. https://doi.org/10.1111/epi.12505

42. la Fougère $C$, Rominger $A$, Förster $S$ et al (2009) PET and SPECT in epilepsy: a critical review. Epilepsy Behav 15:50-55

43. Hamandi K, Powell HWR, Laufs H et al (2008) Combined EEG-fMRI and tractography to visualise propagation of epileptic activity. J Neurol Neurosurg Psychiatry 79:594-597. https://doi.org/10.1136/jnnp.2007.125401

44. Kima JS, Koo DL, Joo EY et al (2016) Asymmetric gray matter volume changes associated with epilepsy duration and seizure frequency in temporal-lobe-epilepsy patients with favourable surgical outcome. J Clin Neurol 12(3):323-331

45. Chen XM, Huang DH, Chen ZR et al (2015) Temporal lobe epilepsy: decreased thalamic resting-state functional connectivity and their relationships with alertness performance. Epilepsy Behav 44:47-54

46. Jain A, Struck AF, Woo KM et al (2018) Thalamic and basal ganglia metabolism on interictal 18F-FDG PET in temporal lobe epilepsy: an SUVbased analysis. Am J Nucl Med Mol Imaging 8(1):41-49

47. Takano A, Shiga T, Kobayashi J et al (2001) Thalamic asymmetry on interictal SPECT in patients with frontal lobe epilepsy. Nucl Med Commun 22:319-324

48. Chang CP, Yen DJ, Yu SM et al (2008) Unilateral thalamic hypometabolism in patients with temporal lobe epilepsy. J Formos Med Assoc 107(7):567-571

49. Hari R, Ahonen A, Forss $\mathrm{N}$ et al (1993) Parietal epileptic mirror focus detected with a whole-head neuromagnetomete. Neuro Report 5:45-48

50. Kim J, Shin H, Hwang KJ et al (2014) Mirror focus in a patient with intractable occipital lobe epilepsy. J Epilepsy Res 4(1):34-37

51. Sharma R (2005) Molecular imaging by proton magnetic resonance imaging (MRI) and MR Spectroscopic Imaging (MRSI) in neurodegeneration. Infor Med Slov 10(1):35-55

52. Burtscher IM, Holtas S (2001) Proton MR spectroscopy in clinical routine. Magn Reson Imaging 44:560-567

\section{Publisher's Note}

Springer Nature remains neutral with regard to jurisdictional claims in published maps and institutional affiliations.

\section{Submit your manuscript to a SpringerOpen ${ }^{\circ}$ journal and benefit from:}

- Convenient online submission

- Rigorous peer review

- Open access: articles freely available online

- High visibility within the field

- Retaining the copyright to your article

Submit your next manuscript at $\boldsymbol{\nabla}$ springeropen.com 